\title{
Repression of PKR mediates palmitate-induced apoptosis in HepG2 cells through regulation of Bcl-2
}

\author{
Xuerui Yang ${ }^{1,2}$, Christina Chan ${ }^{1,2}$ \\ ${ }^{I}$ Department of Chemical Engineering and Materials Science, Michigan State University, East Lansing, MI 48824, USA; ${ }^{2}$ Depart- \\ ment of Biochemistry and Molecular Biology, Michigan State University, East Lansing, MI 48824, USA
}

The present study shows that double-stranded RNA-dependent protein kinase (PKR) regulates the protein expression level and phosphorylation of Bcl-2 and plays an anti-apoptotic role in human hepatocellular carcinoma cells (HepG2). In various types of cells, saturated free fatty acids (FFAs), such as palmitate, have been shown to induce cellular apoptosis by several mechanisms. Palmitate down-regulates the activity of PKR and thereby decreases the level of Bcl-2 protein, mediated in part by reduced activation of the NF- $\mathrm{B}$ transcription factor. In addition to the level of Bcl-2 protein, the phosphorylation of Bcl-2 at different amino acid residues, such as Ser70 and Ser87, is also important in regulating cellular apoptosis. The decrease in the phosphorylation of Bcl-2 at Ser70 upon exposure to palmitate is mediated by inhibition of PKR and possibly by c-Jun N-terminal kinase (JNK), whereas the phosphorylation of Bcl-2 at Ser87 is unaffected by palmitate or PKR. In summary, PKR mediates the regulation of the protein level and the phosphorylation status of Bcl-2, providing a novel mechanism of palmitate-induced apoptosis in HepG2 cells. Keywords: palmitate, apoptosis, HepG2, PKR, phosphorylation of Bcl-2, NF-кB, JNK

Cell Research (2009) 19:469-486. doi: 10.1038/cr.2009.25; published online 3 March 2009

\section{Introduction}

The double-stranded RNA-dependent protein kinase (PKR) is best known for triggering cell defense responses by activating cellular apoptosis during viral infection [1]. Foreign double-stranded RNA (dsRNA), a by-product of viral RNA polymerases during virus replication, binds PKR, facilitating the homo-dimerization and autophosphorylation at Thr451 and Thr446 and thereby the activation of PKR $[2,3]$. The activated PKR, known as a

\footnotetext{
Correspondence: Christina Chan

Tel: +1-517-432-4530; Fax: +1-517-432-1105

E-mail: krischan@egr.msu.edu

Abbreviations: PKR (double-stranded RNA-dependent protein kinase); HepG2 (human hepatocellular carcinoma cells); Bcl-2 (B-cell leukemia/ lymphoma 2); FFA (free fatty acid); NF- $\mathrm{B}$ (nuclear factor kappa B); JNK (c-Jun N-terminal kinase); eIF-2 $\alpha$ (eukaryotic initiation factor 2-alpha); MAPK (mitogen-activated protein kinase); ERK (extracellular-signalregulated kinase); PP2A (protein phosphatase 2A); IKK (I-kB kinase); NAFLD (non-alcoholic fatty liver disease); TG (triacylglycerol); Bim (Bcl-2interacting mediator of cell death); FoxO (forkhead box-containing protein, class O); ROS (reactive oxygen species); RNAi (RNA interference); LDH (lactate dehydrogenase); HCV (hepatitis C virus); ASK1 (apoptosis signalregulating kinase 1)

Received 18 July 2008; revised 10 September 2008; accepted 7 October 2008; published online 3 March 2009
}

eukaryotic initiation factor 2-alpha (eIF-2 $\alpha$ ) kinase, induces the phosphorylation of eIF- $2 \alpha$ at Ser51 [3], which inhibits the initiation of translation by the tRNA-40S ribosomal subunit. This function of PKR results in the inhibition of general protein synthesis and the induction of cellular apoptosis in many types of eukaryotic cells [3, 4]. However, evidence is emerging, albeit controversial at this point, that PKR also has an anti-apoptotic role in mouse embryo fibroblasts and certain tumor cells [5-9].

As a Ser/Thr protein kinase, PKR is known for its role in mediating signaling pathways [10] by interacting with proteins such as NF- $\kappa$ B, MAPKs, and PP2A [11$14]$. PKR phosphorylates and thereby releases $I-\kappa B$ from $\mathrm{NF}-\kappa \mathrm{B}$, thus activating NF- $\mathrm{B}$ and promoting the translocation of NF- $\kappa B$ into the nucleus $[11,12]$. On activation of NF- $\kappa \mathrm{B}$ by PKR, the transcription of a number of apoptosis-regulating genes, such as FasL [15], p53 [16], and cIAPs [5], has been shown to be up-regulated. PKR plays a crucial role in the phosphorylation of the three mitogen-activated protein kinases (MAPK) (JNK, ERK, and $\mathrm{p} 38$ ) upon ribotoxic stress [13]. However, the mechanism by which PKR interacts with the major MAPKs, as well as whether its role is apoptotic or anti-apoptotic, is unclear. PKR can also phosphorylate the PP2A regulatory subunit B56 $\alpha$ and thus activate the catalytic subunit 
of PP2A, potentially leading to the dephosphorylation of eIF-4E and the arrest of translation [14].

In addition to dsRNA, PKR has been shown to be responsive to many other factors (e.g., endoplasmic reticulum (ER) stress [17, 18], cytokines such as tumor necrosis factor (TNF)- $\alpha$ [19] and interleukin (IL)-1 [20], deoxynivalenol (DON, or vomitoxin) [13] and lipopolysaccharide [20]). The present study shows for the first time that palmitate down-regulates the activity of PKR in human hepatocellular carcinoma cells (HepG2) cells.

Saturated free fatty acids (FFAs) (e.g., palmitate) induce apoptosis in many cell types, such as cardiac cells, pancreatic beta cells, breast cancer cells, and hepatocytes. They are associated with the development of a variety of diseases, including diabetes, heart disease, and non-alcoholic fatty liver disease (NAFLD) [21, 22]. The mechanism by which palmitate induces apoptosis depends on the cell type. For example, palmitate induces apoptosis by generating intracellular reactive oxygen species (ROS) in microvascular endothelial cells (EC) and retinal pericytes [23], but not in neonatal rat cardiomyocytes [24]. Studies of palmitate-induced apoptosis in liver cells have focused predominantly on lysosomal permeabilization [25], intracellular metabolic pathways such as beta oxidation [26], TG accumulation [27, 28], and ceramide production $[29,30]$. In addition, increased hydrogen peroxide $\left(\mathrm{H}_{2} \mathrm{O}_{2}\right)$ and hydroxyl $\left({ }^{*} \mathrm{OH}\right)$ radicals were shown to mediate the palmitate-induced lipotoxicity in the human hepatocellular carcinoma (HepG2/C3A) cell line [31]. However, cytotoxicity, as well as apoptosis, was not completely prevented upon treatment with mitochondrial complex inhibitors or free radical scavengers, suggesting that mechanisms other than ROS production in mitochondria contribute to the toxicity of palmitate.

More recent investigations implicate certain Bcl-2 family proteins in mediating the saturated FFA-induced apoptosis of liver cells. For example, palmitate-induced apoptosis in liver cells is related to the activation $[25,32]$ of Bax and a decrease in the Bax antagonist Bcl-xL [25]. In addition, elevated Bcl-2-interacting mediator of cell death (Bim), a pro-apoptotic Bcl-2 family protein, plays a role in stearic and palmitic acid-induced apoptosis of several liver cell lines including HepG2 [32, 33]. This process depends on the transcription factor FoxO3a [32]. In addition to these pro-apoptotic Bcl-2 family proteins, an anti-apoptotic member, Bcl-2, has been identified as an important factor in regulating the apoptosis of HepG2 cells [34-36]. In pancreatic cells, the induction of apoptosis by palmitate is associated with reduced anti-apoptotic Bcl-2 levels [37]. We previously showed that palmitate also decreased the protein level of Bcl-2 in HepG2 cells [38]. The present study confirms a similar effect of palmitate on the levels of Bcl-2 and provides a potential mechanism; furthermore, it shows that palmitate also down-regulates the phosphorylation of Bcl-2 at Ser70, but not at Ser87, in HepG2 cells.

As one of the most important anti-apoptotic members in the Bcl-2 family, Bcl-2 protects cells against intrinsic apoptosis by maintaining the integrity of the mitochondrial membrane [39]. Expression of the Bcl-2 gene is regulated by different transcription factors depending on the cell type [40-42]. In tumor cell lines such as U937 and HepG2 cells, NF- $\mathrm{KB}$ has been identified as the central regulator of the transcription of the Bcl-2 gene [43, 44]. Bcl-2 is expressed in the progenitor cells of several self-renewing tissues and some tumor cells, including HepG2 cells [45-48]. Immunohistochemical studies indicate that Bcl-2 is not expressed in primary hepatocytes [45], although a more recent study with "high-power" staining shows Bcl-2 expression in primary hepatocytes [49]. In the present study, we confirm by both RT-PCR and western blotting that HepG2 cells express Bcl-2, and we propose a pathway through which palmitate regulates the Bcl-2 protein in HepG2 cells.

Post-translational modification (e.g., phosphorylation) of Bcl-2 also plays a role in determining the antiapoptotic role of Bcl-2 [50]. Phosphorylation of Bcl-2 at the anti-apoptotic site, Ser70, sustains the anti-apoptotic role of Bcl-2 [51]. On the other hand, phosphorylation of Bcl-2 at Ser87 is believed to reduce the anti-apoptotic function of Bcl-2, possibly by inhibiting the phosphorylation of Bcl-2 at Ser70 or destabilizing the Bcl-2 protein $[52,53]$. MAPKs have been proposed to mediate the phosphorylation of Bcl-2 [54-58] because the sequences surrounding both Ser70 and Ser87 residues of the Bcl-2 protein represent the consensus motif, X-X-S-P, recognized by MAPKs [58]. PP2A, a Ser/Thr-specific protein phosphatase, has been shown to dephosphorylate Bcl-2 at both Ser70 [59] and Ser87 [53] residues.

The data in the present study support the action of PKR as an anti-apoptotic factor and demonstrate that PKR is involved in regulating the protein level and phosphorylation of Bcl-2 in HepG2 cells. There has been no evidence in the literature to date indicating whether palmitate has an effect on the activity of PKR. We show that palmitate down-regulates the activity of PKR, which, however, does not alter the phosphorylation level of eIF$2 \alpha$, and we propose that the repression of PKR mediates apoptosis through the regulation of $\mathrm{Bcl}-2$.

\section{Results}

Palmitate induces cytotoxicity and apoptosis of HepG2 cells Previous work in our lab showed that palmitate in- 
duced cytotoxicity in HepG2 cells, whereas unsaturated FFAs (e.g., oleate and linoleate) were not cytotoxic [31, $60]$. In a separate study, we found that upon exposure to palmitate, the HepG2 cells stained positive for Annexin$\mathrm{V}$ (data not shown), which indicates phosphatidylserine externalization, a sign of early-stage apoptosis. In the present study, we further found that palmitate increased lactate dehydrogenase (LDH) release and caspase-3 activity of HepG2 cells in a dose-dependent manner, whereas oleate did not have a significant effect on LDH release and caspase- 3 activity (Figure 1A and 1B), supporting the idea that palmitate induces cytotoxicity and apoptosis in HepG2 cells. It has also been confirmed in the literature that palmitate induces apoptosis of HepG2 cells $[32,33]$.

\section{Palmitate decreases the activity of PKR in HepG2 cells}

Palmitate decreased the phosphorylation of PKR at Thr451, which indicates the activity of PKR, in a dosedependent manner (Figure 2A), whereas the unsaturated FFA oleate did not significantly affect the phosphorylation of PKR (Figure 2B) in HepG2 cells. Considering the apoptotic effects of palmitate on HepG2 cells (Figure 1B), we hypothesize that in HepG2 cells PKR is involved in mediating the apoptosis induced by palmitate. To uncover the role of PKR in regulating apoptosis, gene silencing and gene over-expression studies were performed.

\section{PKR is anti-apoptotic in HepG2 cells}

The small interfering RNA (siRNA) targeting PKR that was employed in the present study markedly inhibited the gene and protein expression of PKR and thereby reduced the level of phosphorylated PKR (Figure 3A). Silencing PKR with this siRNA increased the activity of caspase-3 significantly (Figure 3B), but did not significantly increase the release of LDH (Figure 3B), and it also induced the fragmentation of chromatin DNA (Figure 3B), suggesting that PKR has an anti-apoptotic role in HepG2 cells. To confirm the role of PKR in apoptosis, we rescued the PKR expression level in PKR-silenced cells and found that the caspase-3 activity was reduced to levels close to that of the control (Figure 3C). Taken together, these results suggest that PKR plays an antiapoptotic role in HepG2 cells. To further confirm a catalytic role of PKR in regulating apoptosis, we inhibited the activity of PKR with a pharmaceutical inhibitor [6163] and found that, similar to the siRNA of PKR, the PKR inhibitor also induced apoptosis in HepG2 cells, as evidenced by caspase- 3 activity and DNA fragmentation (Supplementary information, Figure S1). Considering the negative effect of palmitate on the activity of PKR, we therefore proposed that palmitate induces apoptosis, in part by repressing PKR.

\section{Palmitate down-regulates the protein expression level of Bcl-2}

Palmitate decreased the protein level of Bcl-2 (Figure $4 \mathrm{~A})$. Oleate did not have a significant effect on the protein level of Bcl-2 (Figure 4B). It was unclear from the literature how palmitate would regulate the $\mathrm{Bcl}-2$ protein. However, as illustrated in Figures 2 and 4, palmitate concomitantly decreased the phosphorylation of PKR and the protein level of Bcl-2, suggesting a potential association between PKR and Bcl-2. To confirm this as-
A

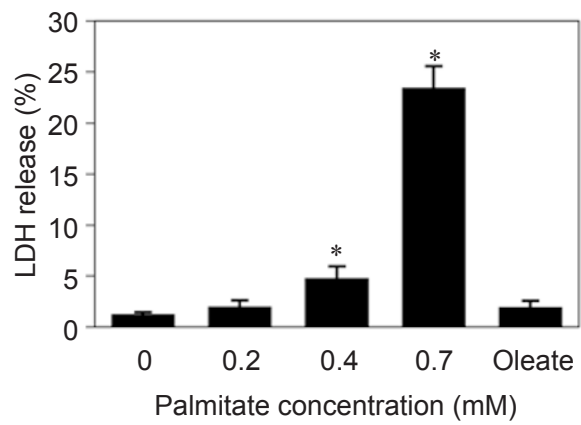

B

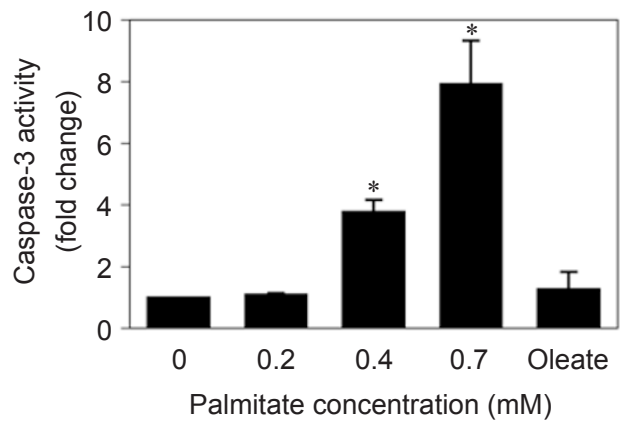

Figure 1 Effects of palmitate on the cytotoxicity and apoptosis of HepG2 cells. HepG2 cells were cultured in regular medium until reaching $\sim 90 \%$ confluency and then exposed to different levels of palmitate or $0.7 \mathrm{mM}$ oleate for $24 \mathrm{~h}$. The vehicle for the FFAs (0.7 mM BSA) was used as the control (i.e., regular medium with BSA) (A, B). LDH release (A) and caspase-3 activity $(B)$ were measured after treatment with palmitate. Data are expressed as the averages of nine samples \pm SD from three independent experiments. One-way ANOVA with Tukey's post hoc method was used to analyze the differences between the treatment groups. *, significantly higher than control (i.e., regular medium with BSA), $P<0.01$. 

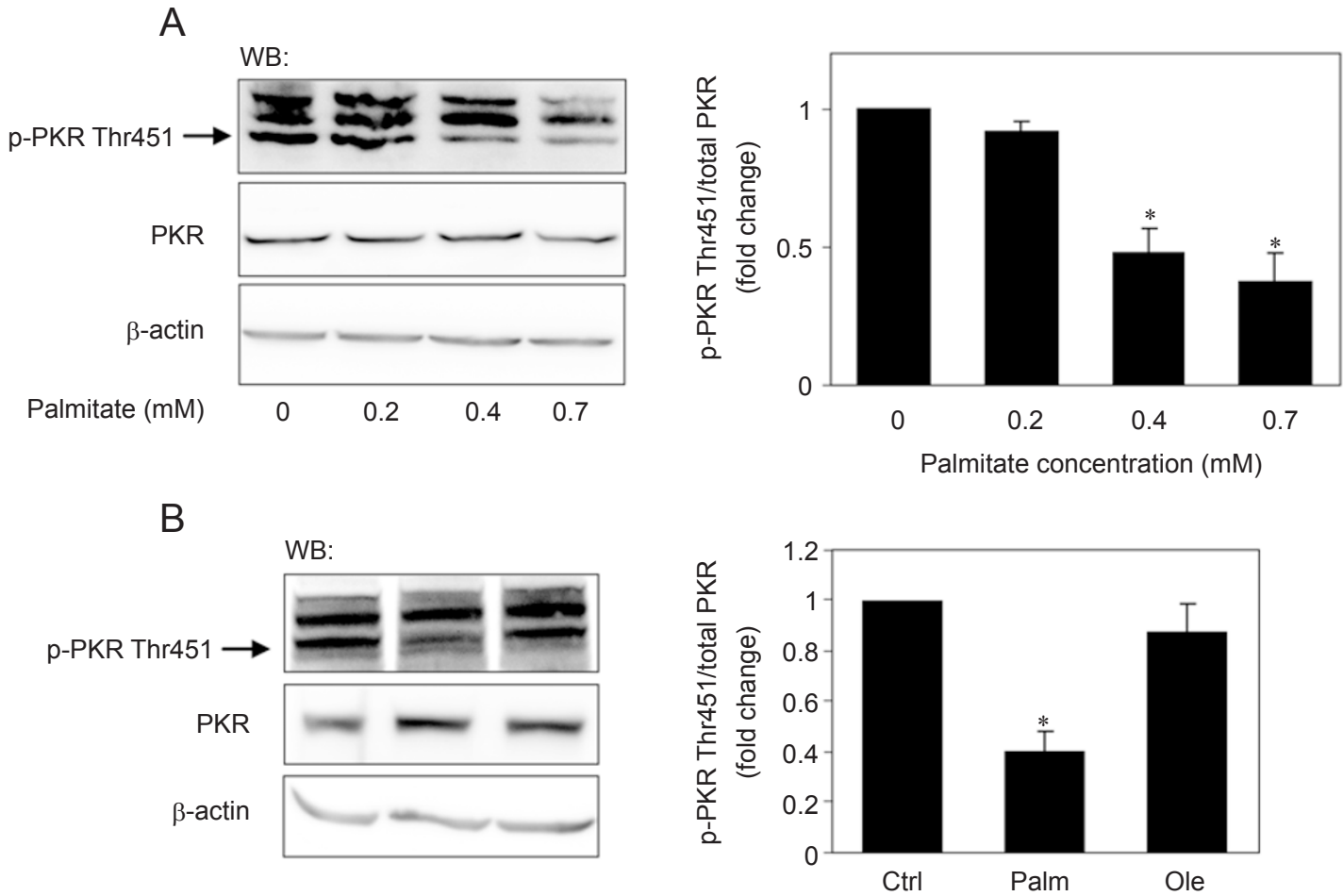

Figure 2 Effects of palmitate and oleate on the activity of PKR. HepG2 cells were cultured in regular medium until reaching $90 \%$ confluency and then exposed to different levels of palmitate (A) or $0.7 \mathrm{mM}$ palmitate or oleate (B) for $24 \mathrm{~h}$. The vehicle for the FFAs (0.7 mM BSA) was used as the control (i.e., regular medium with BSA), in which the concentration of FFAs was 0 (A, B). After treatment, the cells were harvested and western blot analysis was performed to detect the phosphorylated level of PKR. The level of p-PKR Thr451 was quantified by normalizing to the levels of total PKR and is expressed as the average of three samples \pm SD from three independent experiments. One-way ANOVA with Tukey's post hoc method was used to analyze the differences between the treatment groups. *, significantly lower than control (i.e., regular medium with BSA), $P<0.01$.

sociation and test the involvement of PKR in mediating the effect of palmitate on Bcl-2, gene silencing and overexpression of PKR were performed.

$P K R$ is involved in mediating the effects of palmitate on the protein level of Bcl-2 in HepG2 cells

Silencing the expression of the PKR gene with siRNA of PKR (Figure 3A) downregulated the mRNA and protein levels of Bcl-2 (Figure 5A and 5B), suggesting that PKR positively regulates the mRNA expression (Figure 5A) and, in turn, the protein level (Figure 5B) of Bcl-2. Similarly, inhibiting the activity of PKR with the PKR inhibitor also suppressed the mRNA and protein levels of Bcl-2 (Supplementary information, Figures S2A and S2B). Considering the repressive effect of palmitate on PKR activity (Figure 2), we hypothesize that the suppression of PKR activity mediates the negative effects of palmitate on Bcl-2 levels. To confirm our hypothesis that PKR is involved in the decrease of Bcl-2 by palmitate, we over-expressed the PKR gene in HepG2 cells (Figure
5C) and exposed the cells to palmitate. We indeed found that the Bcl-2 level was rescued by over-expression of PKR (Figure 5C). This suggests that the suppression of PKR activity indeed mediates the decrease of Bcl-2 induced by palmitate.

Thus far, we showed that palmitate down-regulated the activity of PKR, a factor with an anti-apoptotic role in HepG2 cells. By suppressing PKR activity, palmitate down-regulated the expression levels of Bcl-2. Although the mechanism is not fully understood, the positive effect of PKR on the anti-apoptotic protein Bcl-2 could serve as a potential pathway by which PKR protects HepG2 cells from apoptosis. PKR phosphorylates $\mathrm{I}-\kappa \mathrm{B}$, which then releases and activates $\mathrm{NF}-\kappa \mathrm{B}[11,12]$, the key transcription factor that up-regulates the transcription of Bcl2 in HepG2 cells [43, 44]. Indeed, silencing the gene expression of PKR decreased the level of NF- $\kappa \mathrm{B}$ in the nucleus (Figure 6A, comparing lanes 1 and 3), whereas over-expressing PKR increased it (Figure 6A, comparing lanes 1 and 2). Moreover, the decreased level of NF-KB 
A
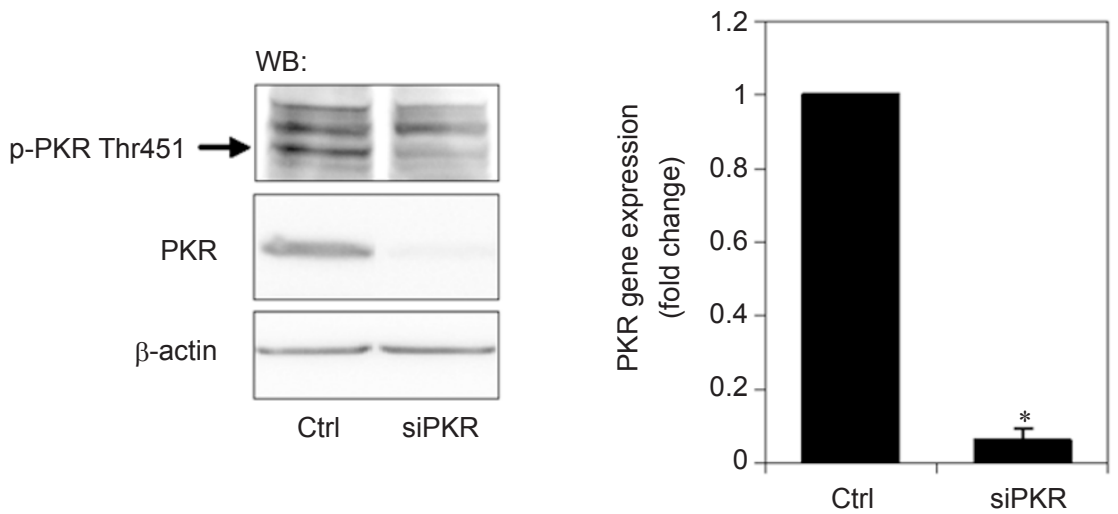

B
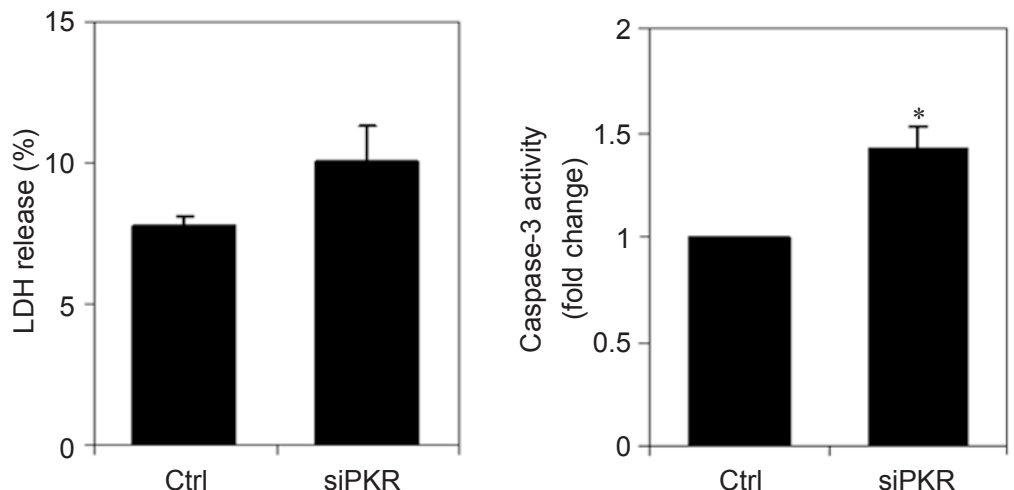

Ctrl siPKR

C

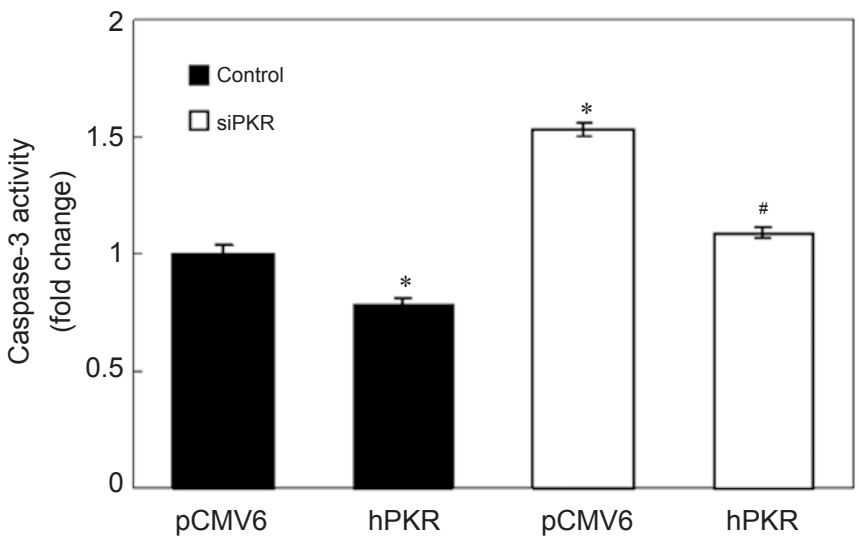

Figure 3 Role of PKR in the cytotoxicity and apoptosis of HepG2 cells. Reverse transfection of suspended HepG2 cells was performed with scrambled siRNA (Control) or siRNA of PKR for $24 \mathrm{~h}$, and the transfected cells were cultured in regular medium for another $24 \mathrm{~h}$ (A, B). Cells were then harvested, and RT-PCR and western blot analysis were performed to detect the gene, protein, and phosphorylation levels of PKR to confirm that the PKR gene was silenced and the activity of PKR was suppressed (A). LDH release, caspase-3 activity, and DNA fragmentation were assayed (B). In (C), reverse transfection of scramble siRNA $(\boldsymbol{\square}$, control) or siRNA of PKR $(\square$, siPKR) was performed, followed by forward transfection of empty vector pCMV6-XL5 (pCMV) or the plasmid containing PKR cDNA sequence (hPKR). Cells were then harvested and caspase-3 activity was assayed $(\mathbf{C})$. Data are expressed as the average of three $(\mathbf{A})$ or nine $(\mathbf{B}, \mathbf{C})$ samples \pm SD from three independent experiments. One-way ANOVA with Tukey's post hoc method was used to analyze the differences between the treatment groups. *, significantly higher $(\mathbf{B}, \mathbf{C})$ or lower $(\mathbf{A}, \mathbf{C})$, than control, $P<0.01$. \#, significantly lower than siPKR-CMV in (C), $P<0.01$. 
A
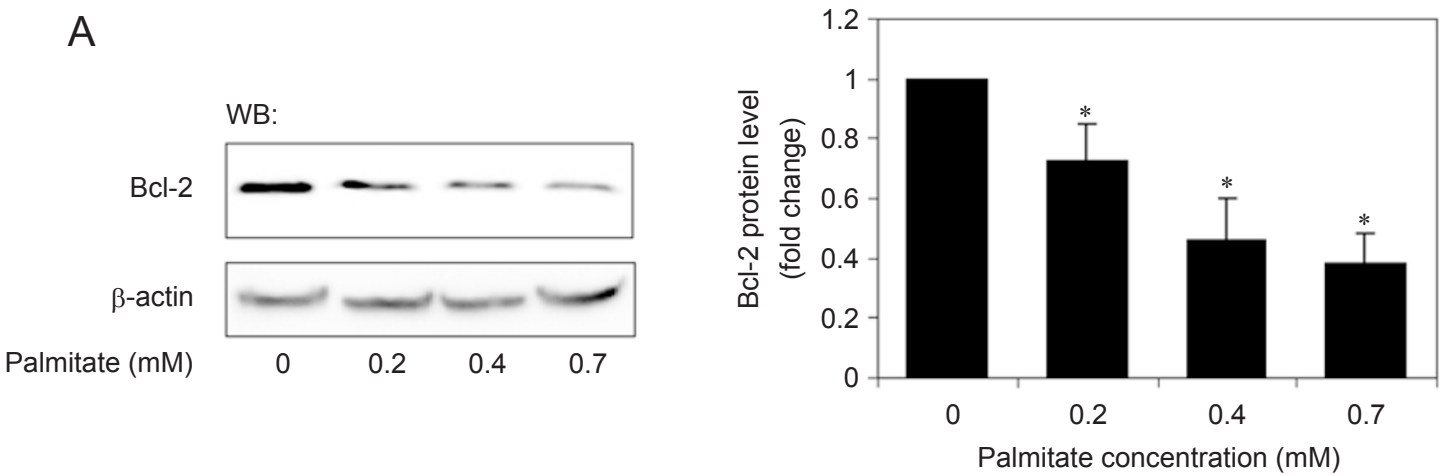

B
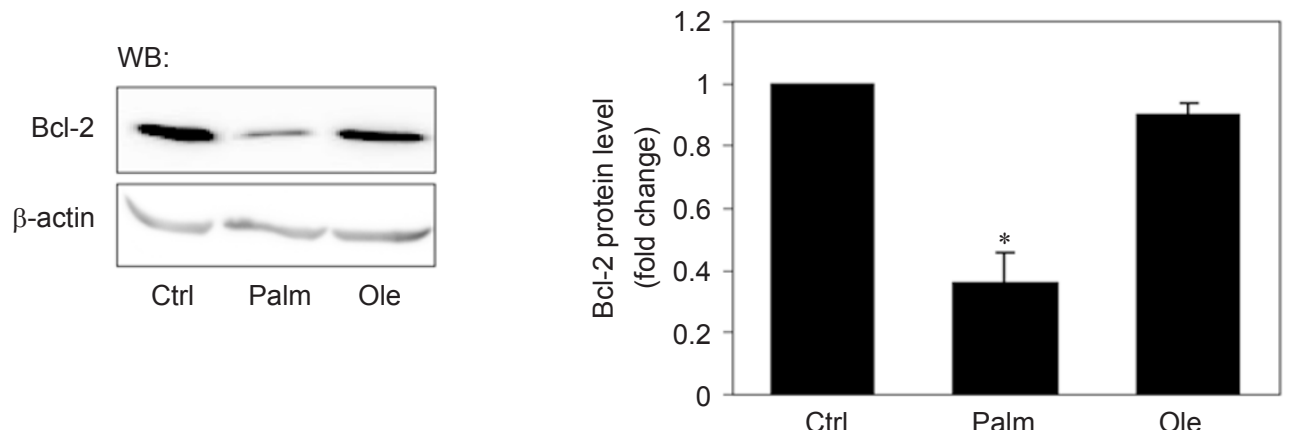

Figure 4 Effects of palmitate and oleate on the protein level of $\mathrm{Bcl}-2$. HepG2 cells were cultured in regular medium until reaching $90 \%$ confluency and then exposed to different levels of palmitate (A) or $0.7 \mathrm{mM}$ palmitate or $0.7 \mathrm{mM}$ oleate (B) for $24 \mathrm{~h}$. The vehicle for the FFAs (0.7 mM BSA) was used as the control (i.e., regular medium with BSA), in which the concentration of FFAs was 0 (A, B). After treatment, the cells were harvested and western blot analysis was performed to detect the protein level of $\mathrm{Bcl}-2$. Bcl-2 protein levels were quantified by normalizing to the $\beta$-actin levels and are expressed as the average of three samples \pm SD from three independent experiments. One-way ANOVA with Tukey's post hoc method was used to analyze the differences between the treatment groups. *, significantly lower than control (i.e., regular medium with BSA), $P<0.01$.

in the nucleus was restored by rescuing the PKR expression in PKR-silenced cells (Figure 6A, comparing lanes 3 and 4). Furthermore, the PKR inhibitor also decreased the level of NF-kB p65 in the nuclear extract of HepG2 cells (Supplementary information, Figure S2B). These results suggest that PKR regulates the activity of $N F-\kappa B$ in HepG2 cells. NF- $\kappa \mathrm{B}$ plays a key role in facilitating the transcription of the Bcl-2 gene in liver tumor cell lines, such as U937 and HepG2 cells, and the inhibition of $\mathrm{NF}-\kappa \mathrm{B}$ results in the down-regulation of $\mathrm{Bcl}-2$ gene expression $[43,44]$. Therefore, it is expected that the protein level of $\mathrm{Bcl}-2$ changes in correspondence with the nuclear level of $\mathrm{NF}-\kappa \mathrm{B}$, as shown in Figure $6 \mathrm{~A}$, in which the gene expression level of PKR is modulated. We further confirmed the role of $\mathrm{NF}-\kappa \mathrm{B}$ in regulating the expression level of $\mathrm{Bcl}-2$ with an inhibitor of $\mathrm{NF}-\kappa \mathrm{B}$, NF- $\kappa$ B SN50 (Figure 6B). Thus, from our results and the literature data, we propose that the transcription factor, $\mathrm{NF}-\kappa \mathrm{B}$, mediates the PKR regulation of $\mathrm{Bcl}-2$ expression in $\mathrm{HepG} 2$ cells. Indeed, we also observed that palmitate decreased the level of NF- $\kappa \mathrm{B}$ in the nucleus (Figure 6C).

In summary, palmitate induces apoptosis of HepG2 cells, in part by reducing the Bcl-2 level, which is mediated by the repression of PKR and NF- $\mathrm{BB}$ activities (Figures 2-6). However, in addition to the protein level of $\mathrm{Bcl}-2$, the anti-apoptotic role of Bcl-2 is also regulated by the post-translational modification of Bcl-2. The phosphorylation of $\mathrm{Bcl}-2$ at Ser70 sustains the antiapoptotic role of Bcl-2, whereas phosphorylation of Bcl2 at Ser87 attenuates the anti-apoptotic role of Bcl-2 [5153]. Therefore, we further investigated the involvement of palmitate and PKR in regulating the phosphorylation of Bcl-2.

Palmitate decreases the phosphorylation of $\mathrm{Bcl}-2$ at Ser70, whereas the phosphorylation of Bcl-2 at Ser87 is not affected

Palmitate decreased the phosphorylation of Bcl-2 at Ser70 in HepG2 cells (Figure 7A). On the other hand, the phosphorylation of Bcl-2 at Ser87 was not affected 
A

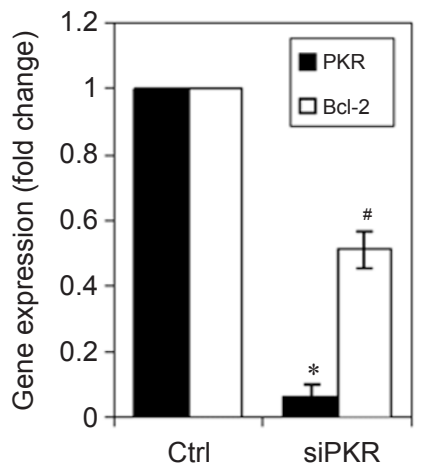

B

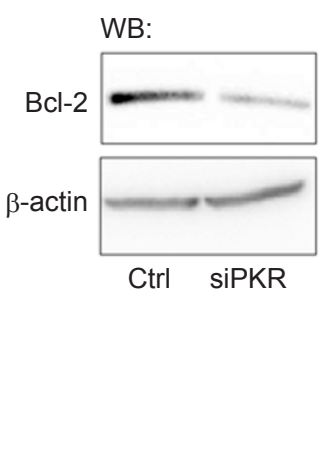

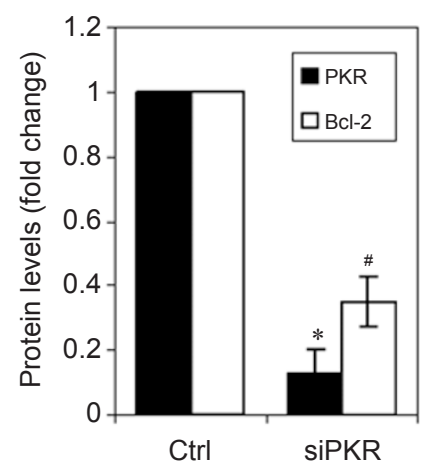

C
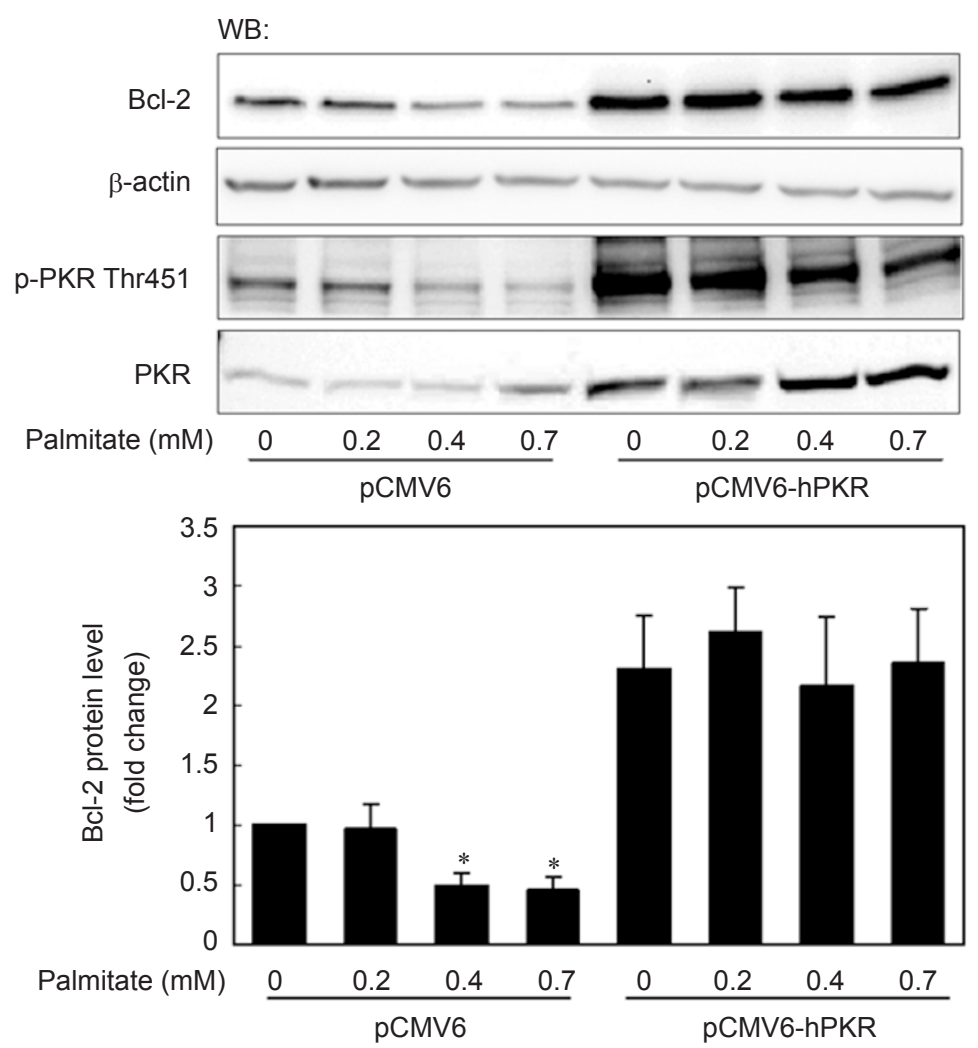

Figure 5 Involvement of PKR in regulating the protein level of Bcl-2. Reverse transfection of suspended HepG2 cells was performed with scrambled siRNA (control) or siRNA of PKR for $24 \mathrm{~h}$ and the transfected cells were cultured in regular medium for another $24 \mathrm{~h}(\mathbf{A}, \mathbf{B})$. Cells were harvested, and RT-PCR (A) and western blot analysis (B) were performed to detect

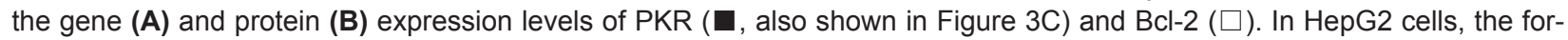
ward transfection of empty vector pCMV6-XL5 (pCMV6) or the plasmid containing PKR cDNA sequence (pCMV6-hPKR) was performed, and the cells were then treated with different concentrations of palmitate for $24 \mathrm{~h} \mathrm{(C)}$. The vehicle for palmitate $(0.7$ mM BSA) was used as the control (i.e., regular medium with BSA), in which the concentration of palmitate was 0 (C). Cells were then harvested and western blot analysis was performed to detect the phosphorylation and protein levels of PKR and the protein levels of $\mathrm{Bcl}-2$ (C). Gene expression data are expressed as the average of nine samples \pm SD from three independent experiments. The protein levels of $\mathrm{Bcl}-2$ were quantified by normalizing to $\beta$-actin and are expressed as the average of three samples \pm SD from three independent experiments. One-way ANOVA with Tukey's post hoc method was used for analyzing the differences between the treatment groups. * and \#, PKR and Bcl-2 levels, respectively, significantly lower than control, $P<0.01$. 

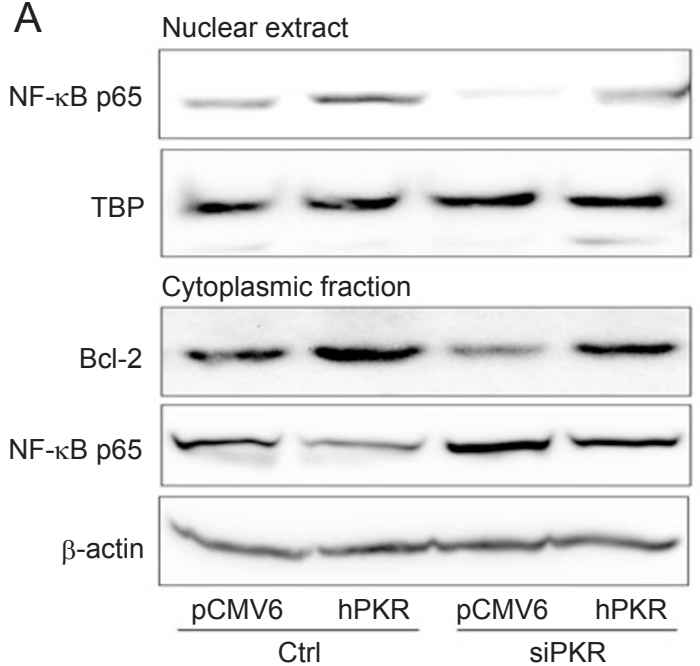

B

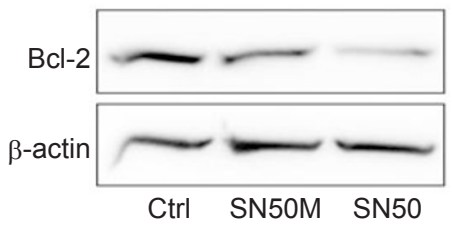

C

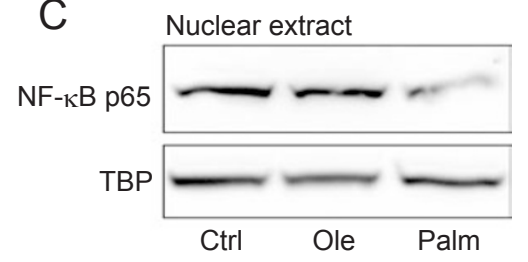

Figure 6 Role of PKR in regulating the nuclear NF-kB p65 level. Reverse transfection of scramble siRNA (control, the first two lanes) or siRNA of PKR (siPKR, the third and fourth lanes) was performed, followed by the forward transfection of empty vector pCMV6-XL5 (pCMV) or the plasmid containing PKR cDNA sequence ( $\mathrm{hPKR}$ ) (A). Cells were then harvested, the nuclear extract was separated from the cytoplasmic fraction, and western blot analysis was performed to detect the level of Bcl2 in the cytoplasmic fraction and the levels of NF-kB p65 in both the nuclear extract and the cytoplasmic fraction. TBP and $\beta$-actin were also measured as loading controls for the nuclear extract and the cytoplasmic fraction, respectively (A). HepG2 cells $(90 \%$ confluent) were exposed to a cell-permeable inhibitor of NF- $\kappa B$, SN50 (18 $\mu \mathrm{M})$, or its negative control, SN50M (18 $\mu \mathrm{M})$, in regular medium for $24 \mathrm{~h}(\mathrm{~B})$. After treatment, the cells were harvested, and western blot analysis was performed to detect the protein levels of Bcl-2 in the whole cell lysates (B). HepG2 cells ( $90 \%$ confluent) were exposed to $0.7 \mathrm{mM}$ palmitate or oleate for $24 \mathrm{~h}(\mathrm{C})$. The vehicle for the FFAs $(0.7 \mathrm{mM} \mathrm{BSA})$ was used as the control (i.e., regular medium with BSA). After treatment, the cells were harvested, and western blot analysis was performed to detect the protein level of NF- $\kappa B$ p65 in the nuclear extracts (C).

A

IP: Bcl-2, IB: p-Bcl-2 Ser70

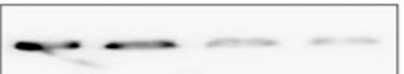

IP: Bcl-2, IB: Bcl-2

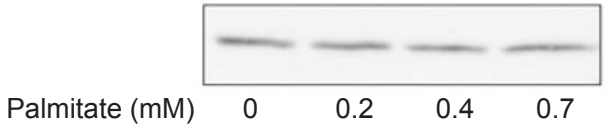

B

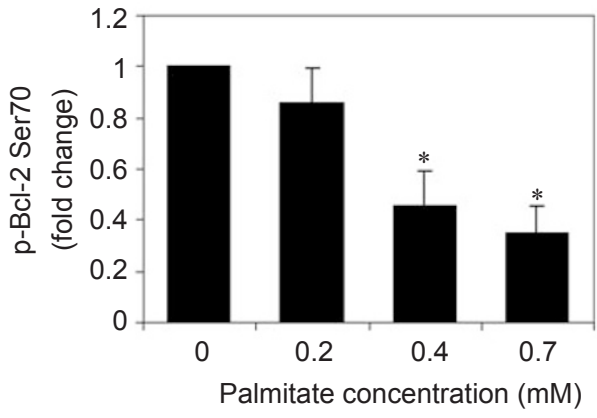

IP: Bcl-2, IB: Bcl-2

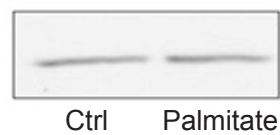

Figure 7 Effect of palmitate on the phosphorylation of Bcl-2. HepG2 cells were cultured in regular medium until reaching $90 \%$ confluency and then exposed to regular medium with different levels of palmitate (A, B) for $24 \mathrm{~h}$. The vehicle for palmitate $(0.7 \mathrm{mM}$ BSA) was used as the control (i.e., regular medium with BSA), in which the concentration of palmitate was 0 (A, B). After treatment, the cells were harvested and immunoprecipitated with anti-Bcl-2 and detected for the phosphorylation of Bcl-2 at Ser70 (A) and Ser87 (B). The phosphorylation levels of Bcl-2 were quantified by normalizing to total Bcl-2 levels and are expressed as the average of three samples \pm SD from three independent experiments. One-way ANOVA with Tukey's post hoc method was used for analyzing the differences between the treatment groups. ${ }^{*}$, significantly lower than control (i.e., regular medium with BSA), $P<0.01$. 
by palmitate (Figure 7B). Considering the concomitant repression of the phosphorylation of Bcl-2 and the PKR activity by palmitate (Figure 2), we hypothesize that $\mathrm{PKR}$, a protein kinase, may be involved in mediating the effects of palmitate on the phosphorylation of Bcl-2.

PKR is involved in mediating the effects of palmitate on the phosphorylation of $\mathrm{Bcl}-2$ at Ser70

Silencing the PKR gene using siRNA of PKR decreased the phosphorylation of Bcl-2 at Ser70 (Figure $8 \mathrm{~A}$ ), indicating that PKR has a positive effect on (i.e., enhances) the phosphorylation of Bcl-2 at Ser70, whereas the phosphorylation of Bcl-2 at Ser87 was not affected by silencing PKR (Figure 8A). The role of PKR in positively regulating the phosphorylation of Bcl-2 at Ser70 is also supported by an inhibition study of PKR (Supplementary information, Figure S2C). The effects of silencing or inhibiting PKR on the phosphorylation of Bcl-2 at
Ser70 and Ser87 are consistent with those of palmitate, and considering the negative effect of palmitate on PKR activity (Figure 2), we propose that the suppression of the PKR activity mediates the negative effects of palmitate on the phosphorylation of Bcl-2 at Ser70, as well as the protein level of Bcl-2. To confirm this hypothesis, we over-expressed the PKR gene in HepG2 cells and exposed the cells to palmitate (Figure 5C). The phosphorylation of Bcl-2 at Ser70 was restored by over-expressing PKR in the palmitate treatment (Figure 8B), supporting the involvement of PKR in mediating the effect of palmitate on the phosphorylation of Bcl-2 at Ser70. However, a co-immunoprecipitation study showed that PKR did not directly interact with the $\mathrm{Bcl}-2$ protein (Figure $8 \mathrm{C}$ ); therefore, other intermediate signaling molecules are involved in mediating the effect of PKR on the phosphorylation of Bcl-2. PKR has been reported to positively regulate MAPKs [13], and sequence analysis of both
A
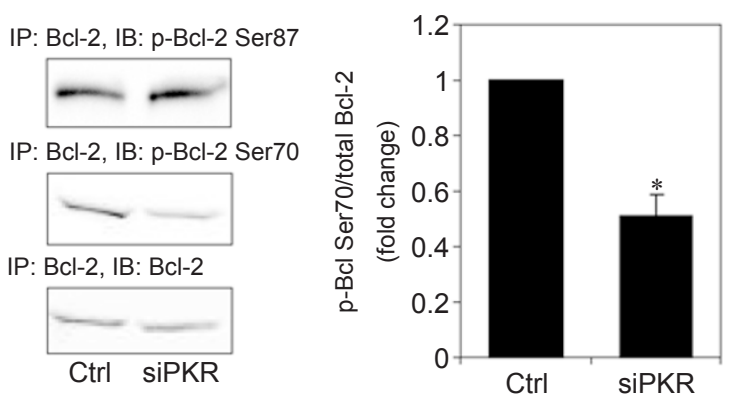

C

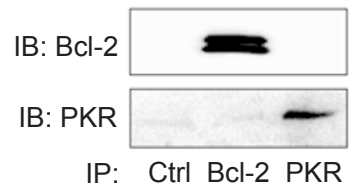

B

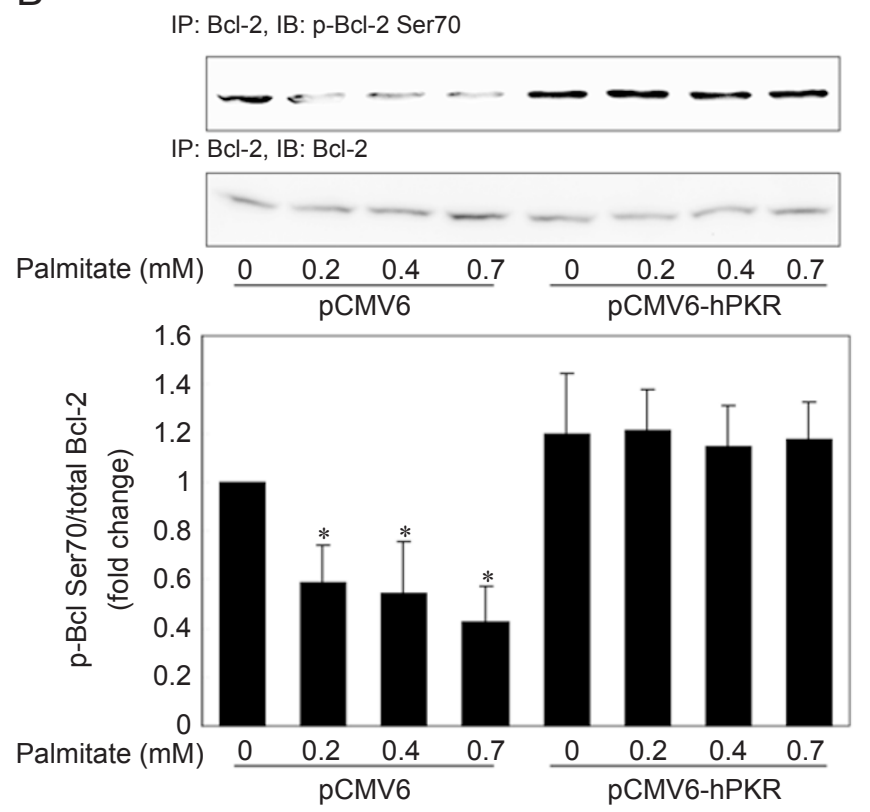

Figure 8 Involvement of PKR in regulating the phosphorylation of Bcl-2 at Ser70. Reverse transfection of suspended HepG2 cells was performed with scrambled siRNA (Control) or siRNA of PKR for $24 \mathrm{~h}$ and the transfected cells were cultured in regular medium for another $24 \mathrm{~h}$ (A). Cells were harvested and immunoprecipitated with anti-Bcl-2 and detected for the phosphorylation of Bcl-2 at Ser70 and Ser87 (A). In HepG2 cells, the forward transfection of empty vector pCMV6-XL5 (pCMV6) or the plasmid containing PKR cDNA sequence ( $p C M V 6-h P K R$ ) was performed and the cells were then treated with different concentrations of palmitate for $24 \mathrm{~h}(\mathrm{~B})$. The vehicle for palmitate $(0.7 \mathrm{mM} \mathrm{BSA})$ was used as the control (i.e., regular medium with $B S A$ ), in which the concentration of palmitate was 0 (B). After the transfections and palmitate treatment, the cells were harvested, and cell lysates were immunoprecipitated with anti-Bcl-2 and detected for phosphorylation of Bcl-2 at Ser70 (B). (Please see Figure 5C for the overexpressed PKR levels.) Confluent HepG2 cells were harvested and immunoprecipitated with anti-Bcl-2 or anti-PKR, and western blot analysis was performed to detect the co-immunoprecipitation of $\mathrm{Bcl}-2$ and PKR (C). The phosphorylation levels of Bcl-2 were quantified by normalizing to total Bcl-2 levels and are expressed as the average of three samples \pm SD from three independent experiments. One-way ANOVA with Tukey's post hoc method was used for analyzing the differences between the treatment groups. *, significantly different from control, $P<0.01$. 
Ser70 and Ser87 residues of Bcl-2 suggests that JNK could regulate the phosphorylation of Bcl-2 [58]. Taken together, the evidence suggests that JNK may act as one of the intermediates between PKR and Bcl-2.

PKR positively regulates $J N K$, and $J N K$ regulates the phosphorylation of Bcl-2 at Ser70, but not at Ser87

A co-immunoprecipitation study indicated that JNK directly interacted with both PKR and Bcl-2 (Figure 9A), suggesting that JNK may be a potential intermediate protein kinase that mediates the positive effect of PKR on the phosphorylation of Bcl-2 at Ser70. Indeed, silencing the PKR gene repressed the activity of JNK (Figure 9B, comparing lanes 1 and 3), whereas over-expressing PKR enhanced it (Figure 9B, comparing lanes 1 and 2). Moreover, the suppressed JNK activity was restored by rescuing the PKR expression in PKR-silenced cells (Figure $9 \mathrm{~B}$, comparing lanes 3 and 4 ), confirming the positive connection between PKR and JNK. Considering the negative effect of palmitate on PKR activity (Figure 2),
A

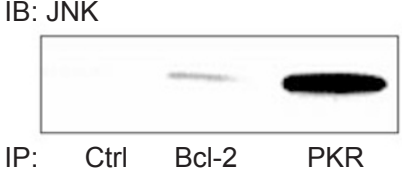

C

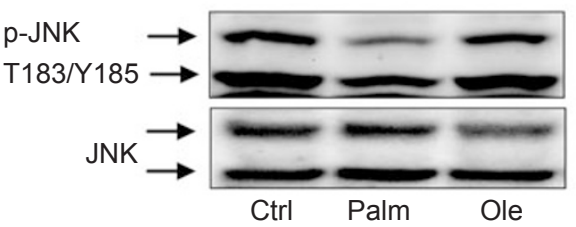

$E$

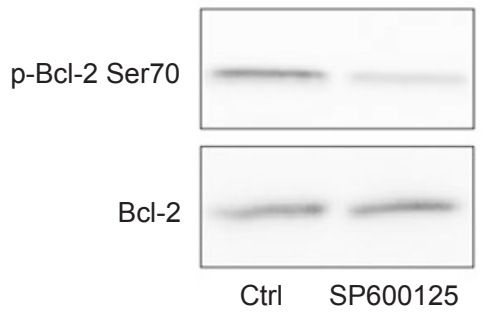

B

$\mathrm{F}$

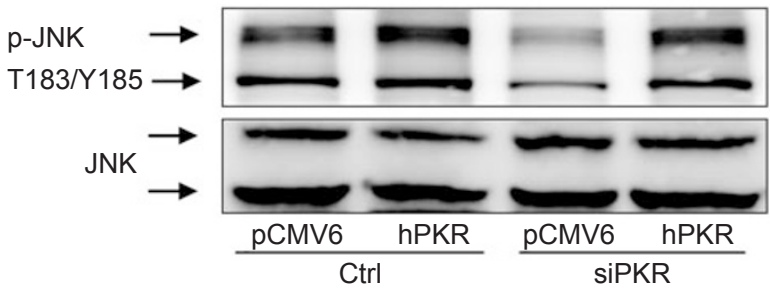

D

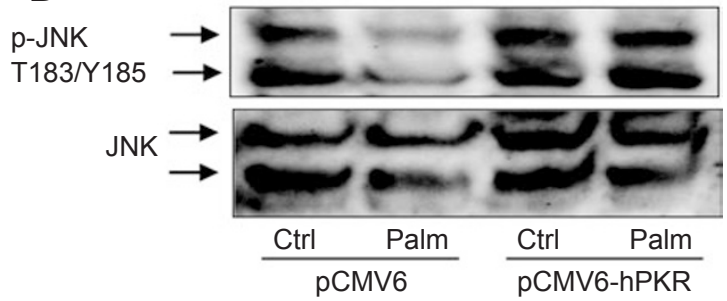

IP: Bcl-2, IB: p-Bcl-2 Ser87

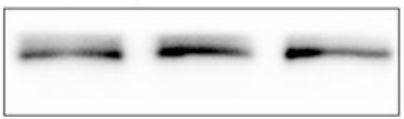

IP: Bcl-2, IB: Bcl-2

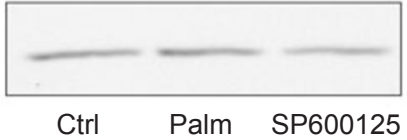

Figure 9 Involvement of JNK in regulating the phosphorylation of Bcl-2. Confluent HepG2 cells were harvested and immunoprecipitated with anti-Bcl-2 or anti-PKR, and western blot analysis was performed to detect the protein level of JNK (A). Reverse transfection of scramble siRNA (control, the first two lanes) or siRNA of PKR (siPKR, the third and fourth lanes) was performed, followed by the forward transfection of empty vector pCMV6-XL5 (pCMV) or the plasmid containing PKR cDNA sequence (hPKR) (B). HepG2 cells (90\% confluent) were exposed to $0.7 \mathrm{mM}$ palmitate or oleate for $24 \mathrm{~h}$ (C). The vehicle for the FFAs, 0.7 mM BSA, was used as the control (i.e., regular medium with BSA) (C). In HepG2 cells, the forward transfection of empty vector pCMV6-XL5 (pCMV6) or plasmid containing PKR cDNA sequence (pCMV6-hPKR) was performed and the cells were then treated with $0.7 \mathrm{mM}$ palmitate for $24 \mathrm{~h}$ (D). The vehicle for palmitate, $0.7 \mathrm{mM} \mathrm{BSA}$, was used as the control (i.e., regular medium with BSA) (D). After treatments, cells were then harvested and western blot analysis was performed to detect the phosphorylation and protein levels of JNK1/2 after treatment (B-D). HepG2 cells (90\% confluent) were exposed in regular medium for $24 \mathrm{~h}$ to the pharmaceutical inhibitor of JNK, SP600125 (25 $\mu \mathrm{M})(\mathrm{E}, \mathrm{F})$, or its analog, SP600125 (25 $\mu \mathrm{M})(\mathrm{E})$, as a negative control. The control in $\mathrm{F}$ is the vehicle of palmitate, BSA. After treatment, the cells were harvested and western blot analysis was performed to detect the protein level of Bcl-2 and the phosphorylation of Bcl-2 at Ser70 (E), or the cell lysate was immunoprecipitated with anti-Bcl-2 and western blot analysis was performed to detect the phosphorylation level of Bcl-2 at Ser87 (F). 
we then propose that palmitate might decrease the activity of JNK by repressing PKR. Indeed, we found that treatment of palmitate for $24 \mathrm{~h}$ decreased the phosphorylation of JNK (Figure 9C), and over-expressing PKR restored JNK phosphorylation (Figure 9D), supporting the involvement of PKR in mediating the effect of palmitate on the phosphorylation of JNK. In addition, to further assess the connection between JNK and Bcl-2, we performed a JNK inhibition study and found that the JNK inhibitor, SP600125, suppressed the phosphorylation of Bcl-2 at Ser70, but not the phosphorylation at Ser87 (Figures 9E and 9F), which is consistent with the distinct effects of palmitate as well as PKR on the phosphorylation of Bcl-2 at the two amino-acid residues (Figures 7 and 8 ). Therefore, the results in Figure 9 suggest that $\mathrm{JNK}$ is an intermediate protein that mediates the effects of palmitate and PKR on the phosphorylation of Bcl-2 at Ser70. We showed that PKR had an anti-apoptotic role in HepG2 cells (Figure 3). To further confirm the positive correlation between PKR and JNK, we investigated the role of JNK in regulating cytotoxicity and apoptosis in HepG2 cells. The inhibition of JNK using SP600125 significantly increased LDH release (Figure 10A) and caspase-3 activity (Figure 10B), suggesting that, similar to PKR, JNK has an anti-apoptotic role in HepG2 cells.

In summary, palmitate inhibits the phosphorylation of Bcl-2 at the anti-apoptotic residue, Ser70, without affecting the pro-apoptotic residue, Ser87. Our data (Figures 7-10) suggest that this effect of palmitate on the phosphorylation of Bcl-2 is mediated by the signaling of PKR and JNK. We therefore propose another anti-apoptotic pathway, which is suppressed by palmitate, consisting of PKR, JNK, and phosphorylation of Bcl-2.

A

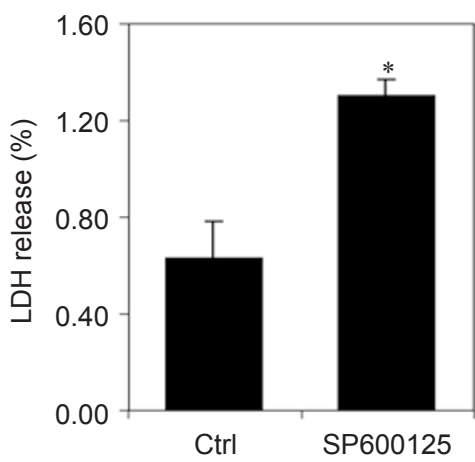

Our investigation of the association between PKR and Bcl-2 revealed two different but complementary antiapoptotic pathways that connect PKR and Bcl-2. First, PKR up-regulates the transcription of the Bcl-2 gene, possibly through the transcription factor, NF- $\kappa \mathrm{B}$. Second, PKR up-regulates the phosphorylation of $\mathrm{Bcl}-2$ at the anti-apoptotic residue, Ser70, mediated by JNK (Figure 11B). These two pathways were down-regulated in HepG2 cells upon exposure to palmitate, and they may constitute one of the mechanisms by which palmitate induces apoptosis in HepG2 cells.

\section{Discussion}

In the present study, we show that PKR is anti-apoptotic in human hepatoma cells. PKR is best known for its pro-apoptotic role by phosphorylating eIF- $2 \alpha$ and thereby inhibiting general protein synthesis $[3,4]$. Thus, it has previously been suggested that PKR acts as a tumor suppressor by inhibiting cell growth and inducing apoptosis $[64,65]$. In contrast, more recent studies suggest that PKR has an anti-apoptotic role in regulating tumor development and tumor-cell apoptosis [6-9]. Elevated PKR protein levels and activity were observed in certain tumor cells (e.g., human breast cancer cells [6], melanoma cells $[7,9]$, and hepatitis C virus (HCV)-related hepatocellular carcinoma [8]). The over-expression and elevated activity of PKR have been attributed to the development of tumors and the proliferation of tumor cells [69], but the mechanism is still unclear. Research suggests that PKR may suppress apoptosis by activating the NF$\kappa \mathrm{B}$ pathway before phosphorylating eIF- $2 \alpha$, therefore inducing cell survival initially and, subsequently, cell

B

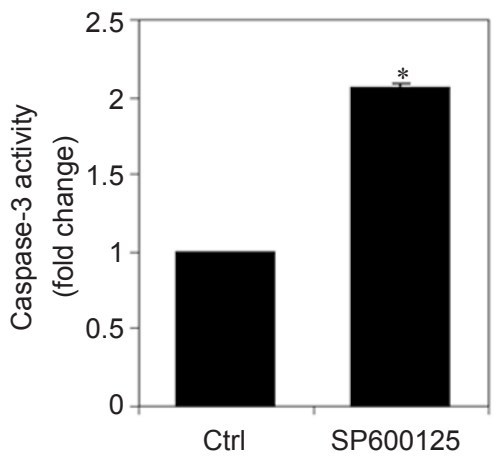

Figure 10 Effect of inhibiting JNK activity on the cytotoxicity and apoptosis of HepG2 cells. HepG2 cells (90\% confluent) were exposed for $24 \mathrm{~h}$ to the pharmaceutical inhibitor of JNK, SP600125 $(25 \mu \mathrm{M})$, or its analog, SP600125 (25 $\mu \mathrm{M})$, as a negative control (A, B). LDH release (A) and caspase-3 activity (B) were measured after treatment with the JNK inhibitor. Data are expressed as the average of nine samples \pm SD from three independent experiments. One-way ANOVA with Tukey's post hoc method was used for analyzing the differences between the treatment groups. *, significantly higher than control, $P<0.01$. 
A

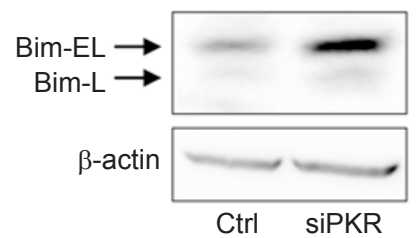

B

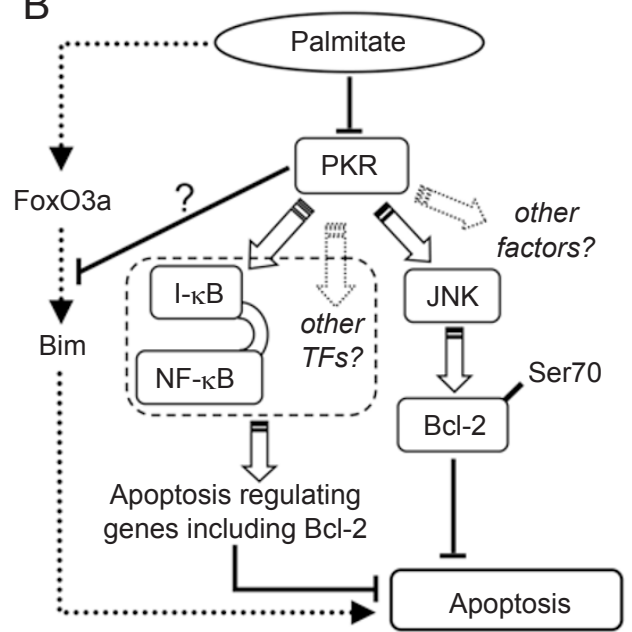

Figure 11 Proposed signaling pathways from PKR to $\mathrm{Bcl}-2$ induced by palmitate. (A) Reverse transfection of suspended HepG2 cells was performed with scrambled siRNA (control) or siRNA of PKR for $24 \mathrm{~h}$ and the transfected cells were cultured in regular medium for another $24 \mathrm{~h}$. Cells were harvested, and western blot analysis was performed to detect the protein level of Bim. (B) A summary of the signaling pathways identified in this study. First, PKR up-regulates the transcription of the $\mathrm{Bcl}-2$ gene through a transcription factor, likely NF-kB. Second, PKR up-regulates the phosphorylation of $\mathrm{Bcl}-2$ at the anti-apoptotic residue Ser70, mediated by JNK. By suppressing PKR, and in turn the two downstream pathways, palmitate regulates the protein level and phosphorylation of $\mathrm{Bcl}-2$ at Ser70 and therefore induces apoptosis in HepG2 cells. Another Bcl-2 family protein, Bim, which also mediates palmitate-induced apoptosis [32, 33] (dashed lines), and the potential effect of PKR on Bim (line with the question mark) are included.

death in NIH3T3 cells expressing PKR [5]. The present study supports an anti-apoptotic role of PKR in HepG2 and suggests potential pathways by which PKR mediates anti-apoptosis through $\mathrm{Bcl}-2$, thereby further providing a potential mechanism of palmitate-induced apoptosis in HepG2 cells. Interestingly, although the phosphorylation of PKR was significantly suppressed in HepG2 cells, by palmitate the phosphorylation level of eIF- $\alpha$ was not altered (Supplementary information, Figure S3). Similarly, another substrate of PKR, B56 $\alpha-P P 2 A$, was not affected by palmitate (Supplementary information, Figure S3).

PKR activates several transcription factors, such as IRF-1, p53, and NF-кB [66, 67]. In the present study, we show that PKR is involved in controlling the transcription of Bcl-2 in HepG2 cells, mediated by the transcription factor $\mathrm{NF}_{-} \kappa \mathrm{B}$. This result suggests a novel mechanism by which palmitate down-regulates the protein level of Bcl-2 (Figure 4) in HepG2 cells. By modulating the transcription of a number of anti-apoptotic genes, such as Bcl-2 [68], Bcl-xL [69], cIAPs [70], and p53 [71], NF$\kappa \mathrm{B}$ is commonly considered an anti-apoptotic transcription factor [72, 73], which is consistent with the antiapoptotic role of PKR in HepG2 cells. NF- $\mathrm{B}$ is the key regulator of transcription of the $\mathrm{Bcl}-2$ gene in liver tumor cell lines, including HepG2 [43, 44]. However, other transcription factors that may regulate the transcription of the Bcl-2 gene, e.g., c-Myb [40, 41] and STAT5 [42], have not been evaluated in the present study. It is not known in the literature whether these transcription factors are altered by palmitate or regulated by PKR. Therefore, it remains to be determined whether other transcription factors, in addition to $\mathrm{NF}-\kappa \mathrm{B}$, also play roles in mediating the effect of PKR on Bcl-2 expression.

Furthermore, other studies have revealed that elevated Bim, a pro-apoptotic Bcl-2 family protein, also plays an important role in the stearic and palmitic acid-induced apoptosis of several liver cell lines, including HepG2 $[32,33]$, and this process has been determined to be dependent on the transcription factor, FoxO3a [32]. In the present study, we propose that the suppression of PKR mediates palmitate-induced apoptosis through $\mathrm{Bcl}-2$; therefore, to test the potential connection between our results and the previous findings on Bim, we evaluated the effect of PKR on the expression of Bim. Interestingly, silencing PKR significantly increased the protein level of Bim (Figure 11A), suggesting that PKR suppresses Bim expression. As a BH3-only Bcl-2 protein, Bim promotes apoptosis by binding and inactivating anti-apoptotic proteins [74]; therefore, the negative effect of PKR on Bim supports the role of PKR as an anti-apoptotic protein and could serve as another potential mechanism by which PKR inhibits apoptosis in HepG2 cells. In addition, we show in the present study that palmitate decreased PKR activity (Figure 2), and thus it is possible that the up-regulation of Bim by palmitate [32] may be due, in part, to the repression of PKR activity. However, the mechanism by which PKR down-regulates the expression of Bim is not known at this point. Future experiments will determine whether PKR has any effect on the key transcription factor of Bim and FoxO3a [32]. Previously, it was shown that PP2A, which was activated by palmitate, mediated the effect of palmitate on the activity of FoxO3a 
and thereby the expression of Bim [32]. However, in our study palmitate did not affect the activity of PP2A (data not shown), and this contradictory result may be due to the different treatment time ( 6 vs. 24 h) and/or the different types of palmitate used (palmitic acid dissolved in isopropyl alcohol vs. sodium palmitate complexed with bovine serum albumin).

In the present study, we uncovered a second antiapoptotic pathway, namely, that PKR up-regulates the phosphorylation of Bcl-2 at Ser70 (Figure 8), mediated by JNK (Figure 9). Although sequence analysis suggests that both Ser70 and Ser87 residues of Bcl-2 can be recognized by JNK [58], we found that only phosphorylation at Ser70 is affected by JNK (Figure 9). Concomitantly, palmitate (Figure 7) and PKR silencing (Figure 8) both decreased only the phosphorylation of Bcl-2 at Ser70, which lends support to the hypothesis that palmitate down-regulates the phosphorylation of Bcl-2 at Ser70 through PKR and JNK. In fact, all three MAPKs are activated by PKR upon ribotoxic stress, and the investigators proposed that MAPKs respond to PKR in the rank order of $\mathrm{JNK}>\mathrm{p} 38>\mathrm{ERK}$ [13]. However, we did not test the effects of PKR on the other two less responsive MAPK proteins, ERK and p38, which were also proposed to phosphorylate Bcl-2 at Ser70 [55-57]. Thus, JNK is one of the intermediates involved in mediating the signaling pathway from PKR to Bcl-2 phosphorylation. Further investigations of the three MAPKs are required to fully understand the interaction between PKR and Bcl-2.

Currently, it remains unclear how PKR interacts with MAPKs (e.g., JNK). An association between PKR and apoptosis signal-regulating kinase 1 (ASK1), one of the MAPK signaling proteins, has been previously established [75]. ASK1, a MAPK kinase kinase (MAPKKK), phosphorylates SEK1/MKK4 and MKK3/MKK6, which, in turn, activate JNK and p38 MAPK, respectively [76]. Our co-immunoprecipitation study suggests an interaction between JNK and PKR (Figure 9). Nevertheless, it must be noted that the co-immunoprecipitation of PKR and JNK does not necessarily indicate a "direct" binding of these two proteins. It is believed that the activation of the MAPK cascade requires a scaffold protein that assembles the MAPKKK, MAPKK, and MAPK proteins together into a certain signaling module [77]. For instance, JIP1 organizes upstream kinase HPK-1, MAPKKK MLK1, MKK7, and JNK1/2, and facilitates the activation of JNK [78]. Therefore, the co-immunoprecipitation study suggests an interaction, but not necessarily a direct one, between PKR and JNK. In other words, the pathway that we identified, consisting of PKR and JNK, does not preclude the possibility of other intermediates between PKR and JNK. To understand how PKR inter- acts with JNK, the scaffold protein and the assembly of the signaling proteins with their upstream activators must be investigated.

JNK is involved in many signaling pathways that control diverse cellular activities, such as proliferation, differentiation, and apoptosis. Through different pathways and substrates [79], JNK has been shown to have either pro- or anti-apoptotic functions, depending on the cell type, stimulus, duration of its activation, and activity of other signaling pathways, and it is therefore considered a "double-edged sword" [80]. In liver tumor cell lines such as HepG2, conflicting views on the role of JNK in regulating apoptosis have been reported in the literature. For example, JNK was shown to mediate anti-apoptotic signals in transforming growth factor-beta 1- [81] and tumor necrosis factor-induced apoptosis [82] in HepG2 cells, whereas other researchers have proposed pro-apoptotic roles for JNK in HepG2 cells [33, 83]. In these studies on the role of JNK in regulating apoptosis, the JNK inhibitor SP600125 was used, and the conflicting results may be due to the different conditions applied by the investigators, such as the concentrations and treatment times of SP600125 and the accompanying additives. In our study, we inhibited JNK in regular medium for $24 \mathrm{~h}$ and found that the JNK inhibitor (SP600125, at $25 \mu \mathrm{M}$ ) was pro-apoptotic, as evidenced by caspase- 3 activity (Figure 10B). Zhang et al. [81] treated liver tumor cell lines with $20 \mu \mathrm{M}$ SP600125 for $50 \mathrm{~h}$, resulting in a significant increase of apoptosis. On the other hand, Chen et al. [83] treated the HepG2 cells with $1 \mu \mathrm{M}$ SP600125 for $48 \mathrm{~h}$ and showed that it blocked the norcantharidininduced apoptosis. Interestingly, in their controls without norcantharidin, SP600125 or ERK inhibitor (U0126 or PD98059) slightly increased the apoptosis of the HepG2 cells, which supports our finding with SP600125 in the control medium. Malhi et al. [33] used SP600125 to inhibit JNK in the presence of palmitic acid for $24 \mathrm{~h}$, but the concentration of the inhibitor used was not specified. Our study suggests that JNK is involved in phosphorylating Bcl-2, an anti-apoptotic member of the Bcl-2 family, at its anti-apoptotic residue, Ser70 (Figure 9C), suggesting that JNK may act as an anti-apoptotic factor. The anti-apoptotic role exhibited by JNK is consistent with that of PKR and therefore lends support to the hypothesis that JNK may mediate, in part, the signaling between PKR and Bcl-2. However, inhibiting JNK with SP600125 also increased the LDH release significantly (Figure 10A), whereas silencing PKR did not have a significant effect on the LDH release (Figure 3B), suggesting that JNK may be involved in other cellular activities related to cytotoxicity, in addition to the pathway from PKR to Bcl2. On the other hand, it is also possible that the inhibitor 
SP600125 itself has other non-specific effects that lead to cytotoxicity, despite its widespread use as an inhibitor of JNK.

The results in the present study show for the first time that palmitate treatment decreases the activity of PKR (Figure 2); however, the mechanism by which palmitate induces dephosphorylation of PKR is still unclear. Palmitate induces a rise in cytosolic free $\mathrm{Ca}^{2+}$ [84], and the depletion of intracellular $\mathrm{Ca}^{2+}$ resulted in the activation of PKR [85]. These findings suggest that the palmitateinduced inactivation of PKR could be mediated by a change in cytosolic $\mathrm{Ca}^{2+}$ level. The auto-phosphorylation of PKR requires its dimerization, which depends on the hydrophobic residues on its catalytic domain [86, 87]. Therefore, a potential interaction between the free palmitate molecules and the hydrophobic residues in the catalytic domain of PKR could disrupt the dimerization of PKR and thereby inhibit its auto-phosphorylation. However, these proposed mechanisms require further investigation.

In summary, we identified an anti-apoptotic role of PKR and found that it is involved in regulating the protein level and phosphorylation status of Bcl-2 in HepG2 cells. The transcription factor NF- $\mathrm{KB}$ and the MAP kinase JNK appear to be involved in mediating the effects of PKR on the protein level and the phosphorylation of Bcl-2, respectively. We propose that palmitate suppresses these two pathways (Figures 4 and 7) by inhibiting PKR (Figure 2) and thereby attenuates the anti-apoptotic machinery (Figure 11B).

\section{Materials and Methods}

\section{Cell culture and reagents}

Human hepatocellular carcinoma cells were cultured in Dulbecco's modified eagle medium (DMEM) (Invitrogen, Carlsbad, CA, USA) with $10 \%$ fetal bovine serum (Biomeda Corp., Foster City, CA, USA) and penicillin-streptomycin (penicillin: 10000 $\mathrm{U} / \mathrm{ml}$, streptomycin: $10000 \mu \mathrm{g} / \mathrm{ml}$ ) (Invitrogen, Carlsbad, CA, USA). Freshly trypsinized HepG2 cells were suspended at $5 \times 10^{5}$ cells $/ \mathrm{ml}$ in standard HepG2 culture medium and seeded at a density of $10^{6}$ cells per well in standard six-well tissue culture plates. After being seeded, the cells were incubated at $37{ }^{\circ} \mathrm{C}$ in a $90 \%$ air $/ 10 \% \mathrm{CO}_{2}$ atmosphere, and $2 \mathrm{ml}$ of fresh medium was supplied every other day to the cultures after removal of the supernatant. The HepG2 cells were cultured in standard medium for 5-6 days to achieve $90 \%$ confluence before treatment with FFAs or other additives. HepG2 cell number was assessed by trypan blue dye exclusion using a hematocytometer. Phosphate-buffered saline (PBS) was purchased from Invitrogen, poly-(I:C) and trypan blue from Sigma-Aldrich (St Louis, MO, USA), and NF-кB SN50 and

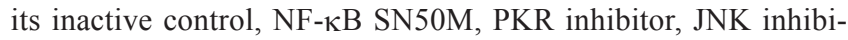
tor (SP600125) and their analogs, used as negative controls, from EMD Biosciences (San Diego, CA, USA).
Fatty acid salt treatment

Sodium salts of palmitate (P9767) and oleate (O7501) were purchased from Sigma-Aldrich. Palmitate and oleate were complexed to $0.7 \mathrm{mM}$ BSA (fatty acid free) dissolved in the medium, which mimics the physiological concentration of albumin in human blood (3.5-5\%, [88]). Fatty-acid-free BSA was purchased from MP Biomedicals (Chillicothe, OH, USA). Dose responses of palmitate at $0,0.2,0.4$, and $0.7 \mathrm{mM}$ were performed in most of the experiments. If only one concentration was reported, the concentration of palmitate or oleate was $0.7 \mathrm{mM}$. In all experiments, FFAs were given for $24 \mathrm{~h}$ and the vehicle $(0.7 \mathrm{mM}$ BSA) was used as the control.

\section{RNA interference for PKR and reverse transfection}

Silencer ${ }^{\circledR}$-validated siRNA targeting human PKR mRNA was purchased from Ambion (Austin, TX, USA). The synthesized oligonucleotides for siRNA are 5'-GGU GAA GGU AGA UCA AAG ATT-3' and 5'-UCU UUG AUC UAC CUU CAC CTT-3'. Reverse transfection of siRNA was performed. In general, the scrambled non-targeting siRNA as a negative control or the siRNA targeting PKR was diluted in serum and antibiotic-free Opti-MEM (Invitrogen) and then mixed with the transfection reagent, Lipofectamine RNAiMAX (Invitrogen). The mixture of siRNA and Lipofectamine RNAiMAX in Opti-MEM was then added into sixwell plates and incubated at room temperature for $20 \mathrm{~min}$. HepG2 cells suspended in antibiotic-free medium were counted and plated into the six-well plates at the same cell number per well. The cells were then incubated at $37{ }^{\circ} \mathrm{C}$ for $24 \mathrm{~h}$. After transfection, the cells were incubated in regular medium for another $24 \mathrm{~h}$ and then collected. The mRNA and protein levels of PKR were measured by RT-PCR and western blot analysis, respectively. Titration of the siRNA and the transfection reagent was performed (not shown), and the lowest working amounts of the siRNA and the transfection reagent were applied in the loss-of-function (LOF) experiments in the present study.

\section{Over-expression of PKR and forward transfection}

The PKR plasmid, pCMV6-XL5-hPKR, and the empty vector, pCMV6-XL5, were purchased from Origene (Rockville, MD, USA). Transient transfection was performed according to the Lipofectamine 2000 (Invitrogen) method. In general, regular HepG2 cells (Figures 5C and 8B), or the cells in which the PKR gene was silenced by the siRNA of PKR (Figure 3C), were washed twice with phosphate-buffered saline, and the medium was replaced with $2 \mathrm{ml}$ of Opti-MEM with $1 \%$ fetal bovine serum. Two micrograms per well of pCMV6-XL5-hPKR or the empty vector pCMV6-XL5 was then mixed with $10 \mu \mathrm{l} /$ well of Lipofectamine 2000 in OptiMEM and $20 \mathrm{~min}$ later the mixture was added to the wells. After $6 \mathrm{~h}$ of transfection, the cells were then cultured in regular medium for $48 \mathrm{~h}$ and subsequently harvested (Figure $3 \mathrm{C}$ ) or treated with palmitate (Figures 5C and 8B).

\section{Cytotoxicity measurement}

HepG2 cells were cultured in different media for $24 \mathrm{~h}$ and the supernatants were collected. Cells were washed with PBS and kept in $1 \%$ triton-X-100 in PBS for $24 \mathrm{~h}$ at $37{ }^{\circ} \mathrm{C}$. The cell lysate was then collected, vortexed for $15 \mathrm{~s}$, and centrifuged at $7000 \mathrm{rpm}$ for $5 \mathrm{~min}$. A cytotoxicity detection kit (Roche Applied Science, Indianapolis, IN, USA) was used to measure the LDH levels in the 
supernatants and in the cell lysates. The fraction of LDH released into the medium was normalized to the total $\mathrm{LDH}$ (LDH released into the medium $+\mathrm{LDH}$ remaining in the cell lysates) [31].

\section{DNA fragmentation}

Treated HepG2 cells were lysed and the DNA was extracted using the DNA purification kit from Promega (Madison, WI, USA). Two micrograms of DNA samples was analyzed by electrophoresis on $1.5 \%$ agarose gels and visualized by SYBR gold staining for $4 \mathrm{~h}$.

\section{Caspase analysis}

For the caspase- 3 substrate cleavage assay, the cells were washed with PBS, lysed, and assayed in a 96-well plate using the caspase-3 cellular assay kit (Biomol, Plymouth Meeting, PA, USA). Fluorescence was measured at emission and excitation settings of 360 and $460 \mathrm{~nm}$, respectively, with a Microplate Spectrofluorometer from Molecular Device (Sunnyvale, CA, USA). The caspase-3 activities were normalized by relative $\beta$-actin levels.

\section{Nuclear extraction and detection of nuclear $N F-\kappa B$ levels}

Nuclear extracts from HepG2 cells were prepared using the $\mathrm{Nu}-$ clear/Cytosol Fraction Kit from BioVision (Mountain View, CA, USA). The extracted nuclear and cytoplasmic protein fractions were subjected to western blot analysis with anti-NF- $\mathrm{B}$ p 65 and anti-TBP, as a loading control for the nuclear extracts, and anti- $\beta$ actin for the cytoplasmic fractions.

\section{Western blot analysis and immunoprecipitation}

The HepG2 cells were washed twice with cold PBS and lysed in $300 \mu \mathrm{l} /$ well of CelLytic M cell lysis buffer (Sigma-Aldrich, USA) supplemented with protease inhibitor cocktail (Roche Applied Science, Indianapolis, IN) and Ser/Thr phosphatase inhibitor cocktail (Sigma-Aldrich). The cell lysate was clarified by centrifugation at $10000 \mathrm{rpm}$ for $15 \mathrm{~min}$, and the supernatant was collected. Total protein levels were quantified by BCA assay kit from Pierce Inc. (Rockford, IL, USA). A total of 20-40 $\mu \mathrm{g}$ of total protein was resolved by SDS-PAGE gels from Bio-Rad, transferred to nitrocellulose membranes, and probed with primary and secondary antibodies. Biotinylated protein ladders (Cell Signaling, Beverly, MA, USA) were loaded to one well of each SDS-PAGE gel, and anti-biotin antibody was used to detect the protein ladders on the western blots. Antibody detection was performed using the enhanced chemiluminescence kit from Pierce Biotechnology and imaged on the Molecular Imager ChemiDoc XRS System from Bio-Rad. For immunoprecipitation, the cell lysates were incubated with appropriate primary antibodies at $4{ }^{\circ} \mathrm{C}$ for $1-2 \mathrm{~h}$, and the immunocomplexes were precipitated in a mixture with protein $\mathrm{A}$ affinity gel (Sigma-Aldrich) by overnight incubation. The immunoprecipitates were washed three times with the cell lysis buffer and boiled in SDS-PAGE sample buffer, and the immune complexes were analyzed by western blot analysis. Phospho site-specific anti-eIF2 $\alpha$ (Ser51) and JNK (T183/Y185), anti-eIF2 $\alpha$, anti-PKR, anti-NF- K p65, and anti-JNK rabbit polyclonal antibodies were purchased from Cell Signaling (Beverly, MA, USA), phospho site-specific anti-PP2A/C (Tyr307) from Abcam (Cambridge, MA, USA), phospho site-specific anti-Bcl-2 (Ser70) from Upstate (Charlottesville, VA, USA), phospho site-specific anti-phospho PKR (Thr451) and Bcl-2 (Ser87) polyclonal antibodies from EMD
Biosciences, and anti-Bcl-2, anti-Bim, anti-TBP, and anti- $\beta$-actin antibodies from Sigma-Aldrich. Anti-PP2A-B56 $\alpha$ and anti-goat secondary antibodies were purchased from Santa Cruz Biotechnology (Santa Cruz, CA, USA). Secondary anti-rabbit and anti-mouse antibodies were purchased from Pierce Biotechnology Inc., USA.

\section{Real-time quantitative RT-PCR analysis}

Total RNA was extracted from cells with the RNeasy mini kit (Qiagen, Valencia, CA, USA) and depleted of contaminating DNA with RNase-free DNase (Qiagen). Equal amounts of total RNA $(1 \mu \mathrm{g})$ were reverse-transcribed using an iScript cDNA synthesis kit (Bio-RAD, CA, USA). The first-strand cDNA was used as a template. The primers used for quantitative RT-PCR analyses of human PKR (5'-CCT GTC CTC TGG TTC TTT TGC T-3' and 5'GAT GAT TCA GAA GCG AGT GTG C-3') [89], human Bcl2 (5'-ACA TCG CCC TGT GGA TGA CT-3', and 5'-TCA CTT GTG GCC CAG ATA GG-3'), and human GAPDH (5'-AAC TTT GGT ATC GTG GAA GGA-3' and 5'-CAG TAG AGG CAG GGA TGA TGT-3') were synthesized by Operon Biotechnologies, Inc. (Huntsville, AL, USA). RT-PCR was performed in $25 \mu 1$ reactions using $1 / 10$ of the cDNA produced by reverse transcription, $0.2 \mu \mathrm{M}$ of each primer, $1 \times$ SYBR green supermix from Bio-RAD, and an annealing temperature of $60{ }^{\circ} \mathrm{C}$ for 40 cycles. Each sample was assayed in three independent $\mathrm{RT}$ reactions and triplicate reactions were performed and normalized to the GAPDH expression levels. Negative controls included the absence of enzyme in the RT reaction and the absence of template during PCR. The cycle threshold (CT) values, corresponding to the PCR cycle number at which the fluorescence emission in real time reaches a threshold above the baseline emission, were determined using MyIQ ${ }^{\mathrm{TM}}$ Real-Time PCR Detection System (Bio-RAD).

\section{Statistical analysis}

All experiments were performed at least three times, and representative results are shown. All data, unless specified, are shown as the mean \pm SD for the indicated number of experiments. Oneway ANOVA with Tukey's post hoc method was used to evaluate statistical significances between different treatment groups. Statistical significance was set at $P<0.01$.

\section{Acknowledgments}

We thank Michael J Opperman for his help with some of the experiments. The work was supported in part by the National Science Foundation (BES 0425821), the Environmental Protection Agency (RD83184701), the Whitaker Foundation, the National Institute of Health (R01GM079688-01, R21CA126136-01, and R21RR024439), and the MSU Foundation and the Center for Systems Biology.

\section{References}

1 Barber GN. The dsRNA-dependent protein kinase, PKR and cell death. Cell Death Differ 2005; 12:563-570.

2 Zhang F, Romano PR, Nagamura-Inoue T, et al. Binding of double-stranded RNA to protein kinase PKR is required for dimerization and promotes critical autophosphorylation events in the activation loop. $J$ Biol Chem 2001; 276:24946-24958. 
3 Taylor SS, Haste NM, Ghosh G. PKR and eIF2alpha: integration of kinase dimerization, activation, and substrate docking. Cell 2005; 122:823-825.

4 Stark GR, Kerr IM, Williams BR, Silverman RH, Schreiber RD. How cells respond to interferons. Annu Rev Biochem 1998; 67:227-264.

5 Donze O, Deng J, Curran J, Sladek R, Picard D, Sonenberg N. The protein kinase PKR: a molecular clock that sequentially activates survival and death programs. EMBO J 2004; 23:564571.

6 Kim SH, Forman AP, Mathews MB, Gunnery S. Human breast cancer cells contain elevated levels and activity of the protein kinase, PKR. Oncogene 2000; 19:3086-3094.

7 Kim SH, Gunnery S, Choe JK, Mathews MB. Neoplastic progression in melanoma and colon cancer is associated with increased expression and activity of the interferon-inducible protein kinase, PKR. Oncogene 2002; 21:8741-8748.

8 Hiasa Y, Kamegaya Y, Nuriya H, et al. Protein kinase R is increased and is functional in hepatitis $\mathrm{C}$ virus-related hepatocellular carcinoma. Am J Gastroenterol 2003; 98:2528-2534.

9 Delgado Andre N, De Lucca FL. Knockdown of PKR expression by RNAi reduces pulmonary metastatic potential of B16-F10 melanoma cells in mice: possible role of NF-kappaB. Cancer Lett 2007; 258:118-125.

10 Williams BR. Signal integration via PKR. Sci STKE 2001; 2001:RE2.

11 Kumar A, Haque J, Lacoste J, Hiscott J, Williams BR. Doublestranded RNA-dependent protein kinase activates transcription factor NF-kappa B by phosphorylating I kappa B. Proc Natl Acad Sci USA 1994; 91:6288-6292.

12 Gil J, Alcami J, Esteban M. Activation of NF-kappa B by the dsRNA-dependent protein kinase, PKR involves the I kappa B kinase complex. Oncogene 2000; 19:1369-1378.

13 Zhou HR, Lau AS, Pestka JJ. Role of double-stranded RNAactivated protein kinase $\mathrm{R}$ (PKR) in deoxynivalenol-induced ribotoxic stress response. Toxicol Sci 2003; 74:335-344.

$14 \mathrm{Xu} \mathrm{Z}$, Williams BR. The B56alpha regulatory subunit of protein phosphatase $2 \mathrm{~A}$ is a target for regulation by doublestranded RNA-dependent protein kinase PKR. Mol Cell Biol 2000; 20:5285-5299.

15 Watanabe MA, Rodrigues Souza L, Murad JM, De Lucca FL. Antitumor activity induced by regulatory RNA: possible role of RNA-dependent protein kinase and nuclear factor-kappaB. Eur J Pharmacol 2003; 465:205-210.

16 Yeung MC, Lau AS. Tumor suppressor p53 as a component of the tumor necrosis factor-induced, protein kinase PKR-mediated apoptotic pathway in human promonocytic U937 cells. $J$ Biol Chem 1998; 273:25198-25202.

17 Onuki R, Bando Y, Suyama E, et al. An RNA-dependent protein kinase is involved in tunicamycin-induced apoptosis and Alzheimer's disease. EMBO J 2004; 23:959-968.

$18 \mathrm{He}$ B. Viruses, endoplasmic reticulum stress, and interferon responses. Cell Death Differ 2006; 13:393-403.

19 Meusel TR, Kehoe KE, Imani F. Protein kinase R regulates double-stranded RNA induction of TNF-alpha but not IL-1 beta mRNA in human epithelial cells. J Immunol 2002; 168:6429-6435.

20 Goh KC, deVeer MJ, Williams BR. The protein kinase PKR is required for p38 MAPK activation and the innate immune response to bacterial endotoxin. EMBO J 2000; 19:4292-4297.

21 Feldstein AE, Werneburg NW, Canbay A, et al. Free fatty acids promote hepatic lipotoxicity by stimulating TNF-alpha expression via a lysosomal pathway. Hepatology 2004; 40:185-194.

$22 \mathrm{Lu} \mathrm{ZH}, \mathrm{Mu}$ YM, Wang BA, et al. Saturated free fatty acids, palmitic acid and stearic acid, induce apoptosis by stimulation of ceramide generation in rat testicular Leydig cell. Biochem Biophys Res Commun 2003; 303:1002-1007.

23 Yamagishi S, Okamoto T, Amano S, et al. Palmitate-induced apoptosis of microvascular endothelial cells and pericytes. Mol Med 2002; 8:179-184.

24 Hickson-Bick DL, Sparagna GC, Buja LM, McMillin JB. Palmitate-induced apoptosis in neonatal cardiomyocytes is not dependent on the generation of ROS. Am J Physiol Heart Circ Physiol 2002; 282:H656-H664.

25 Feldstein AE, Werneburg NW, Li Z, Bronk SF, Gores GJ. Bax inhibition protects against free fatty acid-induced lysosomal permeabilization. Am J Physiol Gastrointest Liver Physiol 2006; 290:G1339-G1346.

26 Giordano A, Calvani M, Petillo O, et al. tBid induces alterations of mitochondrial fatty acid oxidation flux by malonylCoA-independent inhibition of carnitine palmitoyltransferase-1. Cell Death Differ 2005; 12:603-613.

27 Listenberger LL, Han X, Lewis SE, et al. Triglyceride accumulation protects against fatty acid-induced lipotoxicity. Proc Natl Acad Sci USA 2003; 100:3077-3082.

28 Srivastava S, Li Z, Yang X, Yedwabnick M, Shaw S, Chan C. Identification of genes that regulate multiple cellular processes/responses in the context of lipotoxicity to hepatoma cells. BMC Genomics 2007; 8:364-379.

29 Wei Y, Wang D, Topczewski F, Pagliassotti MJ. Saturated fatty acids induce endoplasmic reticulum stress and apoptosis independently of ceramide in liver cells. Am J Physiol Endocrinol Metab 2006; 291:E275-E281.

30 Assimacopoulos-Jeannet F. Fat storage in pancreas and in insulin-sensitive tissues in pathogenesis of type 2 diabetes. Int J Obes Relat Metab Disord 2004; 28 Suppl 4:S53-S57.

31 Srivastava S, Chan C. Hydrogen peroxide and hydroxyl radicals mediate palmitate-induced cytotoxicity to hepatoma cells: relation to mitochondrial permeability transition. Free Radic Res 2006; 41:38-49.

32 Barreyro FJ, Kobayashi S, Bronk SF, Werneburg NW, Malhi H, Gores GJ. Transcriptional regulation of Bim by FoxO3A mediates hepatocyte lipoapoptosis. J Biol Chem 2007; 282:2714127154.

33 Malhi H, Bronk SF, Werneburg NW, Gores GJ. Free fatty acids induce JNK-dependent hepatocyte lipoapoptosis. J Biol Chem 2006; 281:12093-12101.

34 Feng LF, Zhong M, Lei XY, Zhu BY, Tang SS, Liao DF. Bcl-2 siRNA induced apoptosis and increased sensitivity to 5-fluorouracil and HCPT in HepG2 cells. J Drug Target 2006; 14:21-26.

35 Handayani T, Sakinah S, Nallappan M, Pihie AH. Regulation of p53-, Bcl-2- and caspase-dependent signaling pathway in xanthorrhizol-induced apoptosis of HepG2 hepatoma cells. Anticancer Res 2007; 27:965-971.

36 Huang DS, Shen KZ, Wei JF, Liang TB, Zheng SS, Xie HY. Specific COX-2 inhibitor NS398 induces apoptosis in human liver cancer cell line HepG2 through BCL-2. World J Gastro- 
enterol 2005; 11:204-207.

37 Landau Z, Forti E, Alcaly M, Birk RZ. Palmitate induced lipoapoptosis of exocrine pancreas AR42J cells. Apoptosis 2006; 11:717-724.

38 Li Z, Srivastava S, Mittal S, Yang X, Sheng L, Chan C. A three stage integrative pathway search (TIPS) framework to identify toxicity relevant genes and pathways. BMC Bioinformatics 2007; 8:202.

39 Breckenridge DG, Xue D. Regulation of mitochondrial membrane permeabilization by BCL-2 family proteins and caspases. Curr Opin Cell Biol 2004; 16:647-652.

40 Salomoni P, Perrotti D, Martinez R, Franceschi C, Calabretta B. Resistance to apoptosis in CTLL-2 cells constitutively expressing c-Myb is associated with induction of BCL-2 expression and Myb-dependent regulation of bcl-2 promoter activity. Proc Natl Acad Sci USA 1997; 94:3296-3301.

41 Taylor D, Badiani P, Weston K. A dominant interfering Myb mutant causes apoptosis in T cells. Genes Dev 1996; 10:27322744.

42 Weber-Nordt RM, Egen C, Wehinger J, et al. Constitutive activation of STAT proteins in primary lymphoid and myeloid leukemia cells and in Epstein-Barr virus (EBV)-related lymphoma cell lines. Blood 1996; 88:809-816.

43 D'Alessio M, Cerella C, Amici C, et al. Glutathione depletion up-regulates Bcl-2 in BSO-resistant cells. FASEB J 2004; 18:1609-1611.

44 Nishikawa T, Nakajima T, Moriguchi M, et al. A green tea polyphenol, epigalocatechin-3-gallate, induces apoptosis of human hepatocellular carcinoma, possibly through inhibition of Bcl-2 family proteins. J Hepatol 2006; 44:1074-1082.

45 Charlotte F, L'Hermine A, Martin N, et al. Immunohistochemical detection of bcl-2 protein in normal and pathological human liver. Am J Pathol 1994; 144:460-465.

46 Terada T, Nakanuma Y. Expression of apoptosis, proliferating cell nuclear antigen, and apoptosis-related antigens (bcl-2, cmyc, Fas, Lewis(y) and p53) in human cholangiocarcinomas and hepatocellular carcinomas. Pathol Int 1996; 46:764-770.

47 Zeppa P, Benincasa G, Fulciniti F, et al. Apoptosis and cytologic differentiation in hepatocellular carcinoma on fine needle aspiration samples. Acta Cytol 1996; 40:861-866.

48 Zhao M, Zhang NX, Economou M, Blaha I, Laissue JA, Zimmermann A. Immunohistochemical detection of bcl-2 protein in liver lesions: bcl-2 protein is expressed in hepatocellular carcinomas but not in liver cell dysplasia. Histopathology 1994; 25:237-245.

49 Pianko S, Patella S, Sievert W. Alcohol consumption induces hepatocyte apoptosis in patients with chronic hepatitis $\mathrm{C}$ infection. J Gastroenterol Hepatol 2000; 15:798-805.

50 Blagosklonny MV. Unwinding the loop of Bcl-2 phosphorylation. Leukemia 2001; 15:869-874.

51 Ito T, Deng X, Carr B, May WS. Bcl-2 phosphorylation required for anti-apoptosis function. J Biol Chem 1997; 272:11671-11673.

52 De Chiara G, Marcocci ME, Torcia M, et al. Bcl-2 phosphorylation by 38 MAPK: identification of target sites and biologic consequences. J Biol Chem 2006; 281:21353-21361.

53 Simizu S, Tamura Y, Osada H. Dephosphorylation of Bcl-2 by protein phosphatase $2 \mathrm{~A}$ results in apoptosis resistance. Cancer Sci 2004; 95:266-270.
54 Srivastava RK, Mi QS, Hardwick JM, Longo DL. Deletion of the loop region of Bcl-2 completely blocks paclitaxel-induced apoptosis. Proc Natl Acad Sci USA 1999; 96:3775-3780.

55 Deng X, Xiao L, Lang W, Gao F, Ruvolo P, May WS Jr. Novel role for JNK as a stress-activated Bcl2 kinase. $J$ Biol Chem 2001; 276:23681-23688.

56 Deng X, Ruvolo P, Carr B, May WS Jr. Survival function of ERK1/2 as IL-3-activated, staurosporine-resistant Bcl2 kinases. Proc Natl Acad Sci USA 2000; 97:1578-1583.

57 Mai H, May WS, Gao F, Jin Z, Deng X. A functional role for nicotine in $\mathrm{Bcl} 2$ phosphorylation and suppression of apoptosis. J Biol Chem 2003; 278:1886-1891.

58 Basu A, You SA, Haldar S. Regulation of Bcl2 phosphorylation by stress response kinase pathway. Int J Oncol 2000; 16:497-500.

59 Ruvolo PP, Deng X, Ito T, Carr BK, May WS. Ceramide induces Bcl2 dephosphorylation via a mechanism involving mitochondrial PP2A. J Biol Chem 1999; 274:20296-20300.

60 Srivastava S, Li Z, Yang X, Yedwabnick M, Shaw S, Chan C. Identification of genes that regulate multiple cellular processes/responses in the context of lipotoxicity to hepatoma cells. BMC Genomics 2007; 8:364.

61 Jammi NV, Whitby LR, Beal PA. Small molecule inhibitors of the RNA-dependent protein kinase. Biochem Biophys Res Commun 2003; 308:50-57.

62 Eley HL, Tisdale MJ. Skeletal muscle atrophy, a link between depression of protein synthesis and increase in degradation. $J$ Biol Chem 2007; 282:7087-7097.

63 Gilfoy FD, Mason PW. West Nile virus-induced interferon production is mediated by the double-stranded RNA-dependent protein kinase PKR. J Virol 2007; 81:11148-11158.

64 Koromilas AE, Roy S, Barber GN, Katze MG, Sonenberg N. Malignant transformation by a mutant of the IFN-inducible dsRNA-dependent protein kinase. Science (New York, NY) 1992; 257:1685-1689.

65 Meurs EF, Galabru J, Barber GN, Katze MG, Hovanessian AG. Tumor suppressor function of the interferon-induced double-stranded RNA-activated protein kinase. Proc Natl Acad Sci USA 1993; 90:232-236.

66 Kumar A, Yang YL, Flati V, et al. Deficient cytokine signaling in mouse embryo fibroblasts with a targeted deletion in the PKR gene: role of IRF-1 and NF-kappaB. EMBo J 1997; 16:406-416.

67 Cuddihy AR, Li S, Tam NW, et al. Double-stranded-RNA-activated protein kinase PKR enhances transcriptional activation by tumor suppressor p53. Mol Cell Biol 1999; 19:2475-2484.

68 Tamatani M, Che YH, Matsuzaki H, et al. Tumor necrosis factor induces Bcl-2 and Bcl-x expression through NFkappaB activation in primary hippocampal neurons. J Biol Chem 1999; 274:8531-8538.

69 Chen C, Edelstein LC, Gelinas C. The Rel/NF-kappaB family directly activates expression of the apoptosis inhibitor Bclx(L). Mol Cell Biol 2000; 20:2687-2695.

70 Wang CY, Mayo MW, Korneluk RG, Goeddel DV, Baldwin AS Jr. NF-kappaB antiapoptosis: induction of TRAF1 and TRAF2 and c-IAP1 and c-IAP2 to suppress caspase- 8 activation. Science 1998; 281:1680-1683.

$71 \mathrm{Wu}$ H, Lozano G. NF-kappa B activation of $\mathrm{p} 53$. A potential mechanism for suppressing cell growth in response to stress. $J$ 
Biol Chem 1994; 269:20067-20074.

72 Kucharczak J, Simmons MJ, Fan Y, Gelinas C. To be, or not to be: NF-kappaB is the answer--role of Rel/NF-kappaB in the regulation of apoptosis. Oncogene 2003; 22:8961-8982.

73 Li M, Shillinglaw W, Henzel WJ, Beg AA. The Rela(p65) subunit of NF-kappaB is essential for inhibiting double-stranded RNA-induced cytotoxicity. J Biol Chem 2001; 276:1185-1194.

74 Willis SN, Adams JM. Life in the balance: how BH3-only proteins induce apoptosis. Curr Opin Cell Biol 2005; 17:617-625.

75 Takizawa T, Tatematsu C, Nakanishi Y. Double-stranded RNA-activated protein kinase interacts with apoptosis signalregulating kinase 1. Implications for apoptosis signaling pathways. Eur J Biochem 2002; 269:6126-6132.

76 Ichijo H, Nishida E, Irie K, et al. Induction of apoptosis by ASK1, a mammalian MAPKKK that activates SAPK/JNK and p38 signaling pathways. Science 1997; 275:90-94.

77 Chang L, Karin M. Mammalian MAP kinase signalling cascades. Nature 2001; 410:37-40.

78 Whitmarsh AJ, Cavanagh J, Tournier C, Yasuda J, Davis RJ. A mammalian scaffold complex that selectively mediates MAP kinase activation. Science 1998; 281:1671-1674.

79 Davis RJ. Signal transduction by the JNK group of MAP kinases. Cell 2000; 103:239-252.

80 Liu J, Lin A. Role of JNK activation in apoptosis: a doubleedged sword. Cell Res 2005; 15:36-42.

81 Zhang H, Ozaki I, Mizuta T, et al. Transforming growth factor-beta 1-induced apoptosis is blocked by beta 1-integrinmediated mitogen-activated protein kinase activation in human hepatoma cells. Cancer Sci 2004; 95:878-886.
82 Liedtke C, Plumpe J, Kubicka S, et al. Jun kinase modulates tumor necrosis factor-dependent apoptosis in liver cells. Hepatology 2002; 36:315-325.

83 Chen YN, Cheng CC, Chen JC, Tsauer W, Hsu SL. Norcantharidin-induced apoptosis is via the extracellular signalregulated kinase and c-Jun-NH2-terminal kinase signaling pathways in human hepatoma HepG2 cells. $\mathrm{Br} J$ Pharmacol 2003; 140:461-470.

84 Remizov O, Jakubov R, Dufer M, et al. Palmitate-induced $\mathrm{Ca}^{2+}$-signaling in pancreatic beta-cells. Mol Cell Endocrinol 2003; 212:1-9.

85 Aktas H, Fluckiger R, Acosta JA, Savage JM, Palakurthi SS, Halperin JA. Depletion of intracellular $\mathrm{Ca}^{2+}$ stores, phosphorylation of eIF2alpha, and sustained inhibition of translation initiation mediate the anticancer effects of clotrimazole. Proc Natl Acad Sci USA 1998; 95:8280-8285.

86 Dey M, Cao C, Dar AC, et al. Mechanistic link between PKR dimerization, autophosphorylation, and eIF2alpha substrate recognition. Cell 2005; 122:901-913.

87 Lemaire PA, Lary J, Cole JL. Mechanism of PKR activation: dimerization and kinase activation in the absence of doublestranded RNA. J Mol Biol 2005; 345:81-90.

88 Peters T. All About Albumin: Biochemistry, Genetics, and Medical Applications. San Diego: Academic Press, 1996.

89 Pataer A, Vorburger SA, Chada S, et al. Melanoma differentiation-associated gene-7 protein physically associates with the double-stranded RNA-activated protein kinase PKR. Mol Ther 2005; 11:717-723.

(Supplementary information is linked to the online version of the paper on the Cell Research website.) 